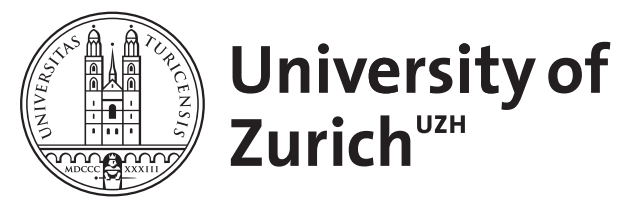

\title{
Value of Aggregators
}

\author{
Akca, Selin ; Rao, Anita
}

\begin{abstract}
Aggregators are facing increased scrutiny by regulatory authorities, suggesting these sites have considerable market power. On the other extreme, firms are bypassing aggregators, choosing instead to sell directly to consumers. This raises the question as to which party has more market power: the aggregator or the individual firm. Focusing on the airline industry, we investigate who benefits most in the airline-aggregator relationship. Specifically, we ask what would happen to airline and aggregator site visits and purchases in the absence of a comprehensive aggregator. We first explore consumers' search patterns on Southwest, an airline that has never been part of any aggregator. In a descriptive exercise, we find that consumers who book on Southwest are the least likely to visit aggregator sites. Second, we use the 2011 American dispute with Orbitz as an exogenous event, which led to American fares no longer being displayed on Orbitz for five months. We use this dispute to identify who was hurt the most - the aggregator or the airline - in the months following the dispute. Our findings indicate the aggregator loses the most when it is not comprehensive.
\end{abstract}

DOI: https://doi.org/10.1287/mksc.2020.1236

Posted at the Zurich Open Repository and Archive, University of Zurich ZORA URL: https://doi.org/10.5167/uzh-190481

Journal Article

Accepted Version

Originally published at:

Akca, Selin; Rao, Anita (2020). Value of Aggregators. Marketing Science, 39(5):893-922.

DOI: https://doi.org/10.1287/mksc.2020.1236 


\title{
Value of Aggregators
}

\author{
Selin Akca \\ Anita Rao \\ UFSP Social Networks \\ Booth School of Business \\ University of Zurich \\ University of Chicago
}

January 2020

\begin{abstract}
Aggregators are facing increased scrutiny by regulatory authorities, suggesting these sites have considerable market power. On the other extreme, firms are bypassing aggregators, choosing instead to sell directly to consumers. This raises the question as to which party has more market power: the aggregator or the individual firm. Focusing on the airline industry, we investigate who benefits the most in the airline-aggregator relationship. Specifically, we ask what would happen to airline and aggregator site visits and purchases in the absence of a comprehensive aggregator. We first explore consumers' search patterns on Southwest, an airline that has never been part of any aggregator. In a descriptive exercise, we find that consumers who book on Southwest are the least likely to visit aggregator sites. Second, we use the 2011 American dispute with Orbitz as an exogenous event, which led to American fares no longer being displayed on Orbitz for five months. We use this dispute to identify who was hurt the most - the aggregator or the airline - in the months following the dispute. Our findings indicate the aggregator loses the most when it is not comprehensive.
\end{abstract}




\section{Introduction}

Search aggregators, such as Google, Kayak, and Expedia, improve consumers' search experience by providing a quick and comprehensive view of all available options, resulting in better matches between consumers and products. Aggregators also help consumers discover new or unfamiliar products (e.g., a niche hotel, a new airline route). However, aggregators are facing increased scrutiny by regulatory authorities who fear that many firms are at the mercy of aggregators and their ranking algorithms ${ }^{1}$. If aggregators have more market power, a firm that is not part of an aggregator risks not being discovered by consumers. On the other extreme, many firms are bypassing aggregators completely, choosing instead to sell directly to consumers. This behavior might arise if firms have more market power and prefer to not be part of an aggregator that makes price comparison easy, increasing price competition and eroding brand value. Who has the upper hand in the firm-aggregator relationship is an increasingly relevant question for regulatory authorities.

Focusing on the airline industry, this paper investigates who benefits the most in the airline-aggregator relationship. Although aggregators help airlines by enabling consumers to find their best match, aggregators need the presence of more airlines to be comprehensive and hence useful to consumers. With airlines questioning the value of search aggregators, we ask what would happen to airline and aggregator site visits and purchases in the absence of a comprehensive aggregator. Enabled by digital technology, airlines are beginning to bypass online ticket aggregators and global distribution systems, preferring to sell directly to consumers. For example, Southwest sells its tickets only on southwest.com and is not available for purchase on any flight aggregator. Disputes between aggregators and airlines over fees have also been on the rise: American pulled its listings from Orbitz in 2011 following a dispute over distribution fees on flight-reservation systems; Delta, in 2013, delisted its flights from several online travel websites.

Using detailed browsing data from comScore, we first document that most consumers use aggregators before making a final purchase at an airline's website. Southwest, which sells tickets only directly through its website, sees an exception to this general behavior: its users are the least likely to visit aggregators. We also document that loyalty to airlines is more common than to aggregators: nearly $52 \%$ of users browse only one airline, while most users use multiple aggregators in their searches.

We next turn to identifying a causal link between aggregator search and airline visits. To do so, we take advantage of a dispute between American airlines and Orbitz surrounding the

\footnotetext{
${ }^{1}$ For example, the EU commission is drafting regulation aimed at increasing transparency as to how search engines, e-commerce sites, and app stores rank their results and why they delist some services (Reuters 2018).
} 
payment of distribution fees. Because of this dispute, American tickets were not displayed on Orbitz for nearly 5 months from December 21, 2010 - June 2, 2011. The dispute created a clear shift in the choice set available to consumers visiting Orbitz, with the timing being driven entirely by the contract renegotiation deadline, thus creating a quasi-experimental setting. Expedia delisted American's flights for a shorter 3 month period from January 1, 2011-April 5, 2011. A Time (2011) article reported, "In bypassing the online travel agents, American saves on distribution costs, but can also raise its ticket prices more easily, since its fares won't be displayed directly beside those of its competitors."

We find that during the dispute period, the aggregator was negatively impacted in both its site visits and purchases. Site visits at Orbitz and Expedia dropped by nearly $11 \%$ and purchases by $2 \%$. On the other hand, American did not experience a significant change in its site visits or purchases. Moreover, we find that consumers living near airports where American is the most important airline continued to use Orbitz and Expedia, perhaps because they knew about American's offerings and used Orbitz and Expedia to learn about other competing offerings. However, consumers near airports where another airline (e.g., United) is the most important, and American is present, were more likely to leave Orbitz and Expedia during the dispute period, likely because without American's information, these sites were not as useful. This dimension of consumer heterogeneity suggests that when an aggregator is not comprehensive, its usefulness drops.

Next, we test two main predictions suggested by the theoretical and empirical literature related to the degree of manufacturer competition and customer loyalty. On competition, the literature suggests manufacturer competition should make for higher retailer market power (O'Brien and Shaffer 1997, Kadiyali et al 2000). Utilizing the variation in the localized nature of airline competition across airports, we find empirical support for this theory. On loyalty, the literature suggests loyalty to the manufacturer can relieve competition thus giving the manufacturer more power. Ailawadi et al (2010) highlight the theoretical work around this. Correspondingly, we expect loyalty to retailers gives the retailer more power. We indeed find the biggest decline in usage of Orbitz and Expedia is among users who are least loyal, i.e., who use multiple aggregators. This analysis provides further evidence of aggregators' limited market power in this industry.

Using the airline origin and destination database (DB1B), a 10\% sample of airline tickets collected by the Bureau of Transportation Statistics, we find evidence that the decline in visits and purchases at the aggregators translates to a decline in American's passenger load. However, this decline is limited to airports where American is not the most important airline and regions where there is low airline competition. This finding highlights the mutual dependence of airlines and aggregators in some areas. 
We also investigate supply side responses such as pricing and advertising changes during the dispute period. We find some evidence suggesting competing aggregators such as Priceline might have increased their Internet ad expenditure. The possibility that competitors might respond further highlights the need for the aggregator to be comprehensive and the dependence of the aggregator on the firm.

Our results have implications for regulatory authorities and policy makers, and suggest aggregators and search engines do not necessarily always have substantial market power. The relationship between firms and aggregators can be industry-specific and needs to be evaluated on a case-by-case basis. In our setting, where there are multiple aggregators which users can easily substitute between and relatively few airlines, we find the aggregator does not have much market power.

\section{Contribution}

Closely related to the incentives at work in this industry, Baye and Morgan (2001) theoretically show that in a homogeneous product market, an aggregator has incentives to gain full consumer participation but keep firm participation partial. This is because when all firms participate, prices drop to marginal costs, removing incentives for the firm to pay a fee to the aggregator or for the consumer to use the aggregator's site. The gatekeeper would rather have some firms not participate to encourage price dispersion. This perhaps can explain why Southwest is not part of an aggregator and advertises itself as a "low-cost" carrier. This can also explain why the disputes lasted only a few months and did not lead to a new equilibrium with airlines permanently absent from aggregators. Our goal is to empirically identify who benefits the most in the airline-aggregator relationship and identify how consumers react to the absence of a prominent airline from an aggregator.

The importance of aggregators has been empirically analyzed in the news industry (Athey et al. 2016, Chiou and Tucker 2017, Calzada and Gil 2016), where similar disputes have arisen between aggregators and news outlets. However, whereas news aggregators can act as complete substitutes to news outlets threatening the outlets' revenue stream, in our setting, the aggregator merely serves as an additional channel, with airlines still earning most of the revenue.

Closely related to this paper, Biltokach, Rupp and Pai (2017) use the American-Orbitz dispute to examine resulting airline fare and demand changes. In contrast, our paper focuses on the impact of the dispute on aggregators to understand who has more market power: airlines or aggregators. Our paper adds to their work by examining detailed browsing-level data to understand consumers' visitation behavior prior to purchase. We also utilize the 
variation in the degree of airline competition at various airports as well as individual-level differences in loyalty towards aggregators to examine heterogenous treatment effects and test various theoretical predictions.

Beyond online domains, aggregators are ubiquitous in the retail channel. The question of who has more market power in the retailer-manufacturer relationship has received a lot of empirical attention in the marketing literature. Ailawadi et al. (2010), in their review paper, highlight the divergent results reported in empirical work. For example, Villas-Boas and Zhao 2005; Draganska et al. 2010 find evidence of manufacturer power while Kadiyali et al. (2000) find evidence of retailer power. In most of these settings, researchers do not observe wholesale prices and/or marginal costs, which makes inference rely on certain modeling assumptions, e.g., assuming a specific competitive structure such as monopolistic retailers. Even when wholesale prices and markups are observed, the counterfactual bargaining outcome is not observed, i.e., what would happen were the manufacturer not present in the retailer's assortment? Therefore, one cannot separately distinguish between manufacturers strong bargaining skills and retailers poor outside options (Noton and Elberg 2018 elaborate on this). One needs to observe entry/exit of manufacturers and episodes of disagreements between the retailer and manufacturer to rightly infer who has more power. We contribute to this literature by providing a setting to infer market power using the exogenous exit of an airline (manufacturer) from an aggregator (retailer) for a finite amount of time.

\section{Institutional Details}

Understanding the reason for the disputes between airlines and aggregators requires an understanding of the way tickets are distributed and the various revenue models in place.

\section{Revenue sources of OTAs and meta-search sites}

Airline search aggregators consist of online travel agencies (OTAs) such as Orbitz and Expedia, and meta-search sites such as Kayak. When a consumer purchases a ticket from an OTA, the OTA earns a commission from the airline. If a consumer uses an OTA to find her best match and then goes on to the airline website to buy her ticket, the OTA does not get paid. Meta-search sites, on the other hand, earn revenues through referral fees from directing consumers to the airline's website, irrespective of whether a purchase is made.

Both OTAs and meta-search sites also earn revenues from ad placements. Booking fees were an additional source of revenue for the OTAs, eliminated prior to the timespan we study in our paper: Priceline and Expedia's Hotwire stopped charging fees in 2007, and Travelocity and Orbitz eliminated fees in 2009. Recently, some of the aggregators have reinstated these 
booking fees. Finally, OTAs earn revenue from hotel and vacation packages. For Orbitz, in 2010, the revenue split was 36\% from Air, 27\% from Hotel, 15\% from Vacation Packages, $7 \%$ from Media and Advertising and the remaining from Other (Orbitz 10K, 2010).

\section{Distribution fees}

All OTAs use global distribution systems (GDSs), which are flight-reservation systems. Every time a ticket is purchased through an OTA, the airline not only pays a commission to the OTA ( $\$ 5)$, but also pays a fee to the GDS ( $\$ 9)$. The GDS then passes approximately $50 \%$ of this fee to the OTA. To avoid paying the distribution fee, airlines have been trying to create their own reservation systems. Another reason for airlines to own their reservation systems is that GDSs do not have the capabilities to showcase add-on features such as upgrades. For these two reasons, American, at the time of its contract renewal in December 2010, wanted Orbitz to use its Direct Connect reservation system instead of relying on Sabre's GDS. Orbitz, however, resisted making the change, because it would mean the loss of nearly half of its revenues whenever an American ticket is booked.

\section{Consumers' valuation of airlines and aggregators}

In the absence of an aggregator, airline visits can decrease, increase, or stay the same: they could decrease if consumers are less likely to find the airline in the absence of the aggregator, they could increase if the value of visiting an additional airline is informative to the consumer, and they could stay the same if visiting additional sites adds no value or is too costly. Similarly, aggregator visits when the aggregator is not comprehensive can either decrease or stay the same.

Consumers typically visit both aggregators and airlines to learn about their best match value. Consumers can gain partial information about airlines by visiting an aggregator, but to learn additional airline-specific details, the consumer has to visit the airline. In addition, aggregators help consumers find their match by increasing their probability of discovering an airline.

Consider a path where a consumer visits the aggregator and one airline before making

her purchase. We now delineate cases where in the absence of an aggregator, airline visits stay the same, increase, or decrease.

1. Airline visits stay the same. This scenario would occur when the consumer knows about and continues to visit the first airline, but the information gain from another airline does not justify the additional visit. 
2. Airline visits increase. Under this scenario, visiting an additional airline is informative to the consumer. Furthermore, she needs to be aware of the existence of this airline, i.e., the probability of discovery is greater than zero.

3. Airline visits decrease. Because the consumer's valuation of visiting the individual airline was high (she visited the airline when the aggregator was present), the only way this scenario would occur is if the probability of discovery drops to 0 ; that is without the aggregator, the consumer is unable to find her true match.

We now delineate cases where, when the aggregator is not comprehensive, aggregator visits can either decrease or stay the same. To simplify the illustration, we assume one airline decides to opt out of being included in the aggregator.

1. Aggregator visits stay the same. This scenario would occur if the absence of the airline does not change the information value drastically; that is it is still worth learning partial information about the remaining airlines.

2. Aggregator visits decrease. When the aggregator is not comprehensive, the partial information available at the aggregator is insufficient to justify the cost of a visit.

Therefore, the true impact of a firm's absence from an aggregator is an empirical one and depends on the context (e.g., the airline industry is likely to behave very differently from the hotel industry).

\section{$3 \quad$ Data and Descriptives}

To understand how consumers search and buy tickets online, we need detailed browsing data that track consumers' website visits across various domains. We use comScore's web behavior database, which consists of a sample of 50,000 internet users randomly chosen from a crosssection of more than 2 million internet users (comScore Database Manual). We supplement this dataset with the Airline Origin and Destination Survey (DB1B) from the Bureau of Transportation Statistics to get measures of demand and prices. The DB1B database is a $10 \%$ sample of airline tickets consisting of origin, operating carrier, number of passengers, and itinerary fare aggregated at the quarterly level every year. The data cover 37 airlines and over 500 airports. We also use the Nielsen Monitor-Plus media database to get measures of ad expenditure by brands across various types of media.

From the comScore database, we select those searches and transactions that pertain to airlines and aggregators. We select the top airlines, by passengers flown as reported in 
the DB1B survey, which have non-zero transactions in the comScore database. We further select those domains that have at least 10,000 visits (searches and transactions) across our panel: the cutoff is at 13,433 visits for Alaska Airlines, with the next popular domain being CheapAir with only 6,608 visits. Table 1 shows the included websites, the total number of search-related visits to each domain, and the number of transactions. We do not include Google Flights and Bing Travel because our data do not distinguish sub-domains, i.e., we cannot identify google.com/flights separately from google.com. Including all of Google's and Bing's searches would increase the size of our data immensely without necessarily increasing the accuracy of our estimates. Moreover, Google Flights was launched in late 2011 and is therefore unlikely to interfere with the dispute period, which was in early 2011.

The number of unique users who visit airline or aggregator websites ranges from 26,00030,000 across the years 2010-2012. comScore tracks the exact timestamp for when a particular website was visited. Each visit comprises a search session, and comScore tracks the duration spent, the number of pages viewed, and whether a transaction was made in that session. Table 2 summarizes these statistics across all users as well as conditional on those users who made a purchase. Furthermore, user demographics such as income, education, and zipcode are present in the dataset.

A majority of visits to airline/aggregator websites ( $55 \%$ ) occur in the month before

purchase, with $80 \%$ occurring within 4 months of the purchase date. We assume that all of these visits and searches are related to the final purchased itinerary. In a robustness check, we verify our results, assuming only site visits one month prior to the last recorded event per user are relevant. Our dataset also includes those searches that did not result in a purchase. Of these, $35 \%$ visit a travel website once and never return over the course of the panel, $12 \%$ search over the course of a month, and the remainder search repeatedly for more than a month but never purchase. Note we do not know if these visits are directed searches toward a purchase, or random visits.

\section{Search patterns on aggregators and airlines}

For every purchased ticket, we identify how many visits were made to an aggregator, the purchased airline, and any non-purchased airline, prior to making a ticket purchase. Figure 1 highlights all possible browsing patterns for a typical airline, using Delta as an example. We see that for a typical airline, the most common search pattern involves visits to all three types of sites: aggregators, the purchased airline, and other airlines. $72 \%$ of all searches involves the use of aggregators at least once. The only airline in contrast to this search pattern is Southwest, which does not participate with any aggregator, where the most common 
Table 1: Total Number of Searches and Transactions on Travel Domains, 2010-2012

\begin{tabular}{|c|c|c|c|c|c|}
\hline \multicolumn{3}{|c|}{ Airlines } & \multicolumn{3}{|c|}{ Aggregators } \\
\hline Domain & Searches & Transactions & Domain & Searches & Transactions \\
\hline aa.com & 57,951 & 1,435 & cheapflights.com & 17,364 & - \\
\hline airtran.com & 22,256 & 889 & cheapoair.com & 63,473 & - \\
\hline alaskaair.com & 12,740 & 693 & expedia.com & 194,459 & 1,878 \\
\hline continental.com & 23,772 & 629 & hotwire.com & 49,894 & 288 \\
\hline delta.com & 67,154 & 1,549 & kayak.com & 58,850 & - \\
\hline jetblue.com & 37,413 & 764 & orbitz.com & 97,961 & 1,439 \\
\hline southwest.com & 100,730 & 6,705 & priceline.com & 107,911 & 1,631 \\
\hline united.com & 32,194 & 821 & travelocity.com & 70,586 & 963 \\
\hline usairways.com & 23,666 & 827 & & & \\
\hline
\end{tabular}

Table 2: Descriptive Statistics: comScore data, Travel Domains 2010-2012

\begin{tabular}{|c|c|c|c|c|}
\hline & \multicolumn{2}{|c|}{ All searches } & \multicolumn{2}{|c|}{$\begin{array}{l}\text { Conditional } \\
\text { on purchase }\end{array}$} \\
\hline & Median & Mean & Median & Mean \\
\hline Number of websites visited & 4.00 & 10.68 & 9.00 & 16.57 \\
\hline Time spent on search (minutes) & 21.00 & 71.62 & 58.00 & 120.30 \\
\hline Total pages viewed & 22.00 & 69.16 & 56.00 & 113.20 \\
\hline Transactions & 0 & 0.25 & 1 & 2.01 \\
\hline Number of unique users & 82,886 & & 10,232 & \\
\hline Total purchases & & & 20,511 & \\
\hline
\end{tabular}

pattern is an user going to Southwest and making a purchase directly without any search. Only $45 \%$ of searches use aggregators. Southwest's search pattern suggests that not being part of an aggregator does not necessarily hurt the airline. Note that these patterns could result if Southwest's customers are very different from other airlines' customers, and also if Southwest allocates marketing resources specifically recognizing it is not part of an aggregator. Moreover, we do not observe the counterfactual of what would happen if Southwest were part of an aggregator. Our empirical exercise in Section 4 will address this issue directly.

Next, we turn to identifying when in the search history aggregators were visited relative to the purchased airline. If consumers are fairly well informed about their destination airline and are merely browsing other websites before making a purchase, we should see the purchased airline being visited earlier. On the other hand, if a consumer searches an aggregator first and then subsequent airlines, we should see aggregators being visited earlier. To study this pattern, we document for all purchased tickets on an airline's domain, the rank order of the purchased airline and of any aggregator. Figure 2 plots these ranks. We observe that 
for most airlines, the aggregator is visited first and then the purchased airline. Exceptions to this pattern are Southwest and Jetblue, the low-cost airlines, where consumers are more likely to visit the purchased airline first.

Last, we document a rough measure of the relative market power of aggregators and airlines using consumers' browsing history. We identify the number of users who browse only a single aggregator, 2-3 different aggregators, or multiple aggregators. We find that the split is roughly a third in each group, i.e. 36\% users browse a single aggregator, $32 \%$ browse $2-3$ aggregators and $32 \%$ browse more than three aggregators. We do the same for airlines. In stark contrast, loyalty to airline domains is much higher. Over $50 \%$ of users browse only a single airline, $34 \%$ browse $2-3$ airlines and the rest browse more than three airlines. Table 3 provides these summary statistics indicating that competition among aggregators is fairly high. Next, we condition on users who browsed a given aggregator atleast once, and repeat the exercise. Table 4 shows the split into each of these three categories, users very rarely browse only one aggregator (7\%-21\%) with Expedia exhibiting the strongest loyalty. Most users browse multiple aggregators. Repeating this exercise for airlines, and consistent with the finding in Table 3, users exhibit more loyalty towards airlines with 17\%-38\% browsing only 1 airline with Southwest exhibiting the strongest loyalty.

Although these patterns indicate the extent to which customers use aggregators to find their ultimate match, and show that being absent from an aggregator is not necessarily harmful to an airline, they do not establish any causal effect. To do so, we turn to the American-Orbitz dispute that resulted in American being unavailable on Orbitz's website for over 5 months. 


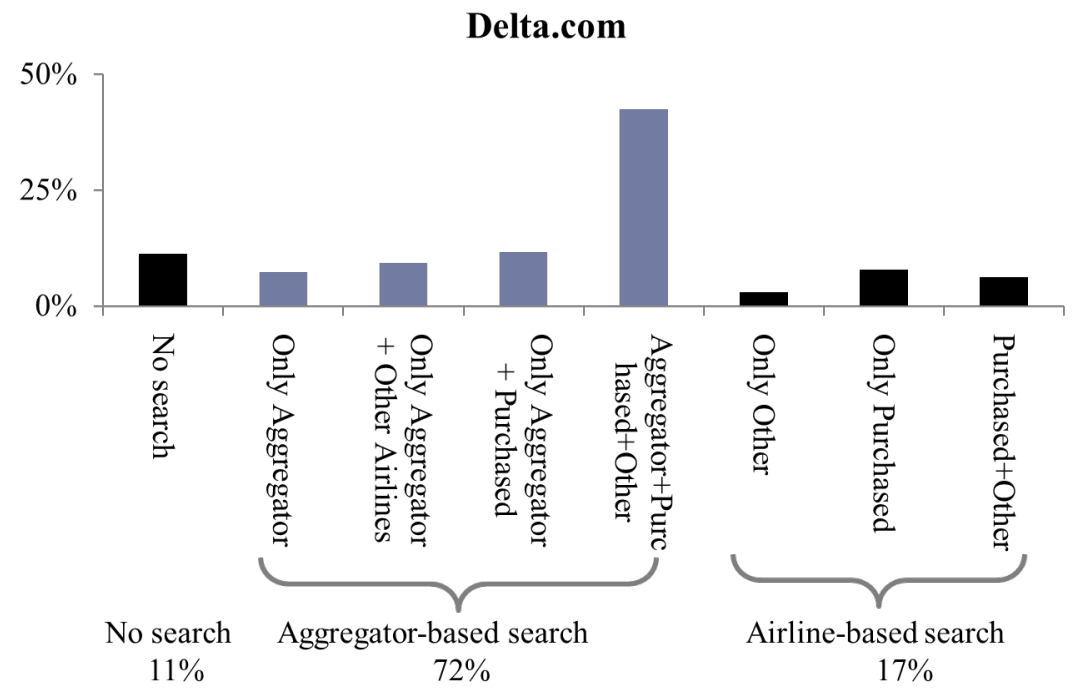

- Delta Southwest

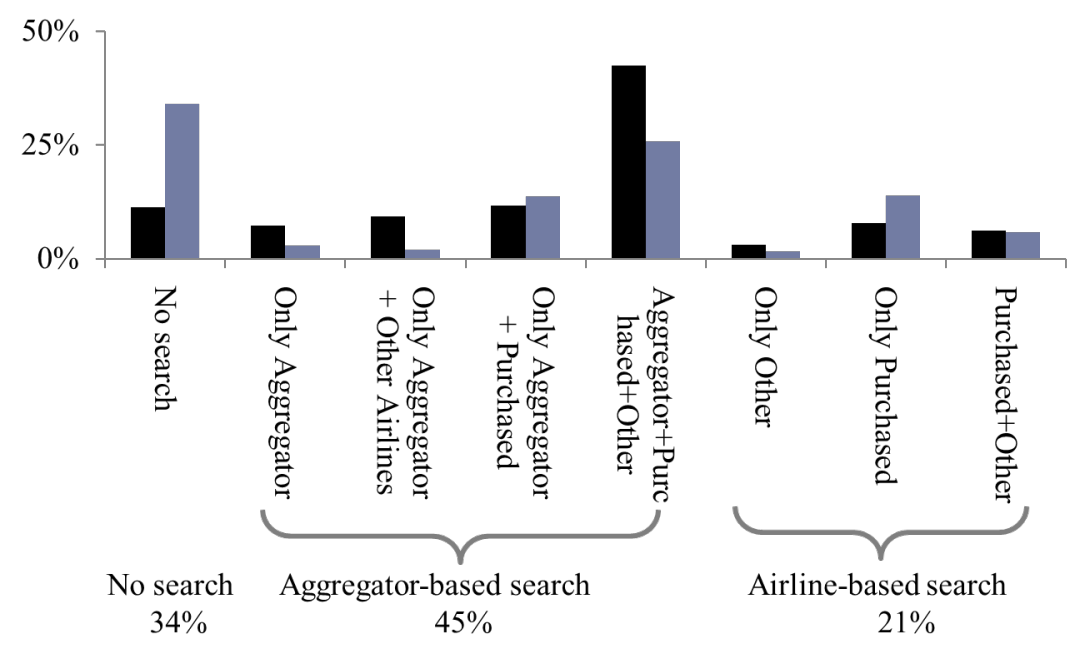

Note: No Search indicates a user visited the site and purchased her ticket in that session. Only Purchased indicates the user visited the purchased airline's site a few times but purchased her ticket after a few such visits. Note these two could be grouped into one category because they both involve only the destination airline.

Figure 1: Southwest users go directly to southwest.com; all other airlines search an aggregator before making a purchase 


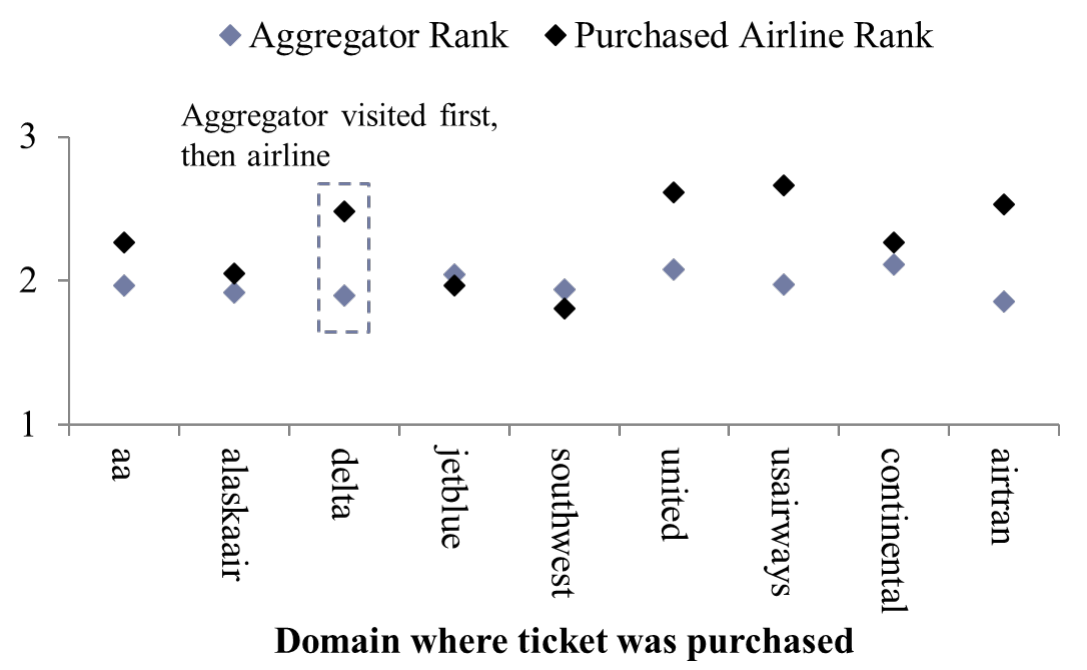

Note: Rank averaged across users, and is determined by order of search per user. As an example, if a user visits an aggregator first and the airline where the ticket was purchased third, the aggregator's rank $=1$ and the purchased airline's rank $=3$.

Figure 2: Consumers start their search at an aggregator, except Southwest and Jetblue users

Table 3: Percent of user who browse few vs. multiple aggregators and airlines

\begin{tabular}{lrlr}
\hline Browse only & $\%$ users & Browse only & $\%$ users \\
\hline 1 aggregator & $36 \%$ & 1 airline & $52 \%$ \\
2-3 aggregators & $32 \%$ & $2-3$ airlines & $34 \%$ \\
$>=4$ aggregators & $32 \%$ & $>=4$ airlines & $14 \%$ \\
\hline
\end{tabular}

Table 4: Of those who browse an aggregator atleast once, how many visit only that aggregator vs. multiple

\begin{tabular}{|c|c|c|c|c|c|c|c|c|}
\hline Browse only & Orbitz & Expedia & Priceline & Travelocity & Kayak & Hotwire & Cheapoair & Cheapflights \\
\hline 1 aggregator & $9 \%$ & $21 \%$ & $12 \%$ & $11 \%$ & $8 \%$ & $7 \%$ & $9 \%$ & $7 \%$ \\
\hline 2-3 aggregators & $28 \%$ & $33 \%$ & $28 \%$ & $26 \%$ & $20 \%$ & $23 \%$ & $22 \%$ & $20 \%$ \\
\hline$>=4$ aggregators & $63 \%$ & $45 \%$ & $59 \%$ & $63 \%$ & $72 \%$ & $69 \%$ & $69 \%$ & $73 \%$ \\
\hline
\end{tabular}

\section{Empirical Evidence}

We use the American-Orbitz dispute to identify the effect of the absence of a major airline from a popular aggregator. We examine both search and purchase behavior during this dispute period and compare it with the same period one year before and one year after. Figure 3 plots the monthly site visits at Orbitz and American as a proportion of visits to all travel websites. Orbitz appears to face a decline in site visits during the dispute period (grey shaded area) in the year 2011, compared to the control periods in 2010 and 2012. American does not seem to be impacted. 
We next turn to the individual level, where for each consumer's itinerary, we construct ${ }^{2}$ three dependent variables:

sites: the number of times a domain's website was visited in a month,

pages: the number of pages viewed at the domain's website that month, and

durn: the duration spent on the website that month.

To account and control for firm-side responses, we construct a measure of advertising spend using the Nielsen Monitor-Plus Media data. The Nielsen data consists of National TV, Spot TV, Internet, Magazines, Newspapers, Outdoors and Radio ad spend along with the airing date and the advertised brand, enabling us to create a domain-month specific advertising spend variable. Ideally, prices would also be included as controls. Unfortunately, we do not observe prices charged by aggregators, and it is also not clear what prices (firmspecific, averaged over multiple firms etc.) one can use for aggregators. We therefore control for prices only in the airline purchase analysis using the DB1B data in Section 4.3, where we observe prices at the airline-quarter level.

We focus on only those months when an individual engaged in a travel-related search. If there is a month in which no travel website is visited by an individual, we do not include that individual-month in the data ${ }^{3}$. We first present how the impacted domains - aa.com, orbitz.com, and expedia.com - perform relative to a control domain and the control period. We then explore which type of consumer the dispute had a greater impact on.

\footnotetext{
${ }^{2}$ When there is no final purchase, we group all the non-purchase-related searches into one itinerary.

${ }^{3}$ In a robustness check, we expand the data to include those months when no travel-related search was performed: this approach allows total searches to increase/decrease. When an individual did not search or visit any given domain in a month, the dependent variables take on the value 0 . Doing so allows for the scenario where consumers increase their total search volume at a given domain when they can no longer find aa.com on an aggregator. The results are fairly similar in this specification but are quantitatively smaller in magnitude because of the large number of additional 0's.
} 
$\%$ Orbitz

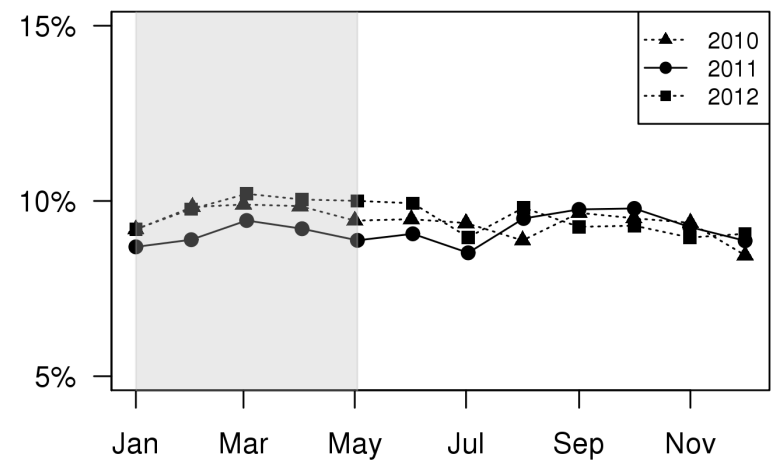

$\%$ American

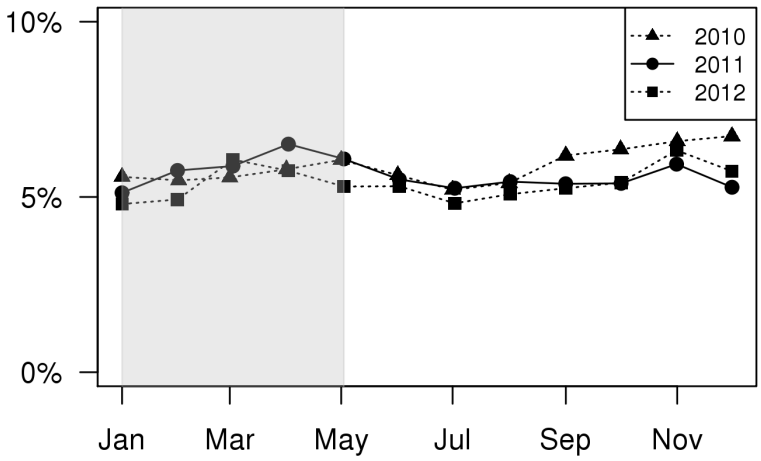

Note: The grey shaded area represents the dispute months, January-May. Year 2011 corresponds to the year of the dispute, 2010 and 2012 serve as control years.

Figure 3: Site visits at Orbitz and American as a percent of site visits at all travel websites

\subsection{Browsing behavior on aggregators and airlines}

For each of the impacted domains, we evaluate the search intensity during the dispute period relative to the same period in the past (2010) and future (2012) years. As controls, we choose the same months when the dispute occurred: January-May but in the previous year and the future year: 2010 and 2012. We focus on the same set of months as the dispute period to hold constant any seasonality patterns that might exist. We conduct a pooled (treating 2010 and 2012 equally) regression. Results are robust to an un-pooled regression (treating the two years separately).

To rule out any industry-wide trend (e.g., delta.com, priceline.com might also be impacted), we further include a control domain against which we compare the change in search intensity. An ideal control should not have spillovers from the treated firms (ruling out all websites where one can book airfare or hotels), but should still face similar travel industry trends. One such candidate is Lonely Planet: a site which is rarely used for booking ${ }^{4}$, and is ranked among the top 15 travel websites (eBizMBA 2020).

One potential concern of using Lonely Planet as a control is that users might use it more for international travel implying lack of similarity between the treated aggregators and Lonely Planet. We therefore check demographics of users of the control and treated firms,

\footnotetext{
${ }^{4}$ During the timespan of our dataset, there are 8232 visits to Lonely Planet, but only 46 referrals from lonelyplanet.com (a 0.5\% conversion rate). In comparison, kayak.com has 58,850 visits and over 24,000 referrals (a $41 \%$ referral rate). Lonely Planet's low conversion/referral rate indicates that users visit lonelyplanet with the intention to learn about the destinations and not to book.
} 
finding that they are highly similar in terms of income, household size, racial background, census region of residence, head of household's age, connection speed, country of origin, and number of children present. Table 24 in Appendix A presents these descriptives for users of each of the domains. We also check parallel trends, between the treated firms and Lonely Planet, in the control period, and find evidence supporting Lonely Planet as a control. Figures 8 and 9 in Appendix A plot these trends for site visits. In addition, we also check the correlations between LonelyPlanet and each of the treated firms' site visits during these months. These correlations, shown in Table 25, Appendix A, are positive and fairly high, especially for Orbitz and Expedia suggesting that LonelyPlanet serves as a good control. However, to avoid concerns that Lonely Planet might not capture industry-wide trends, we conduct additional analyses using alternative controls in Section 4.1.1.

For each of the impacted domains, we estimate the following regression separately:

$$
\begin{aligned}
y_{i j t} & =\beta_{0} D_{t}+\beta_{1} D_{t} \times \text { Disp }_{Y} \\
& +\beta_{0}^{F} D_{t} \times \text { Focal }_{j}+\beta_{1}^{F} D_{t} \times \text { Disp }_{Y} \times \text { Focal }_{j} \\
& +\alpha_{t Y}+\alpha_{t Y}^{F} \text { Focal }_{j}+\alpha_{i}+\gamma \text { Ad } d_{j t}+\varepsilon_{i j t}
\end{aligned}
$$

where $i$ is the individual, $j$ is the domain, and $t$ is time in months. Here, $y_{i j t}$ is the dependent variable sites, durn and pages, $D_{t}=1$ if $t$ is between January and May, the months relevant to the dispute period in either the treated or untreated years, $\operatorname{Disp}_{Y}=1$ if the months correspond to the year the dispute occurred (2011). Focal ${ }_{j}$ is an indicator that equals 1 if travel domain $j$ is the impacted domain, i.e., American, Orbitz, or Expedia. $\beta_{0}$ and $\beta_{1}$ capture the average estimate of the control site(s) during the control and dispute periods respectively (relative to the estimates in the rest of the year), $\beta_{0}^{F}$ and $\beta_{1}^{F}$ capture the additional change specific to the impacted domain's website in the control and dispute periods respectively. $\beta_{1}^{F}$ is the treatment effect of the dispute period. $\alpha_{t Y}$ is the year fixed effect that controls for any year-specific trends in the industry, $\alpha_{t Y}^{F}$ is the year fixed effect for the impacted domain that controls for any year-specific trends in that domain, and $\alpha_{i}$ is the individual fixed effect. $A d_{j t}$, the advertising spend of firm $j$ in month $t$, is included to control for any firm-side responses that might influence search intensity. Standard errors are clustered at the individual level.

Table 5 presents the results of this analysis, using Lonely Planet as the control. The results show both Orbitz and Expedia experience a significant decline in site visits and duration spent by users. Site visits decline by 0.041 for Orbitz and 0.061 for Expedia. To put these numbers in context, the average number of site visits per month at Orbitz is 0.38 which implies a $11 \%$ drop in site visits, an economically meaningful drop. We discuss the further implications of this drop in Section 4.5. The results also show a statistically insignificant 
increase in site visits to aa.com. Figure 4 plots the increase/decrease in duration and site visits across all three websites.

Discussion on page views In Table 5, we see a decrease in page views to aa.com. To further investigate this pattern in page visits, we run a zero-inflated poisson regression which separates out the number of zero visits from those who visit, and conditional on those visiting, helps understand their behavior changes. Following Lambert (1992), we specify page views follow the distribution:

$$
y_{i j t} \sim \begin{cases}0 & \text { with probability } p_{i j t} \\ \text { Poisson }\left(\lambda_{i j t}\right) & \text { with probability } 1-p_{i j t}\end{cases}
$$

where $\lambda_{i j t}=\exp (\beta X) . \beta X$ uses the same specification as equation 1 . The portion that accounts for the excess zeros, $p_{i j t}$, is modeled using a logit model, such that $p_{i j t}=\frac{\exp (\zeta X)}{1+\exp (\zeta X)}$ where $\zeta X$ is the same specification used in equation 1. Table 6 presents the results of this regression. From this table, we see that aa.com sees more visitors: the coefficient for the zero-inflated part of the regression is negative and significant indicating a drop in number of zero-visits. However, conditional on a visit, aa.com sees fewer page views. We believe this occurs because of the selection of consumers visiting the site during the dispute period. More people visit aa.com during the dispute, but might not find a good match and hence do not browse as many pages, as consumers who come there with greater certainty of booking. 
Table 5: Searches on impacted domains, relative to LonelyPlanet and pooled control period

\begin{tabular}{lrrrrrrrr}
\hline \multirow{2}{*}{$\begin{array}{l}\text { (1) sites } \\
\end{array}$} & \multicolumn{2}{c}{ aa.com } & \multicolumn{2}{c}{ orbitz.com } & \multicolumn{2}{c}{ expedia.com } \\
& \multicolumn{2}{c}{ coeff } & t-stat & coeff & t-stat & coeff & t-stat \\
\hline Jan-May & $\beta_{0}$ & 0.009 & 3.52 & 0.013 & 3.82 & 0.015 & 3.53 \\
Jan-May X Dispute & $\beta_{1}$ & -0.004 & -0.80 & -0.001 & -0.13 & 0.005 & 0.67 \\
Jan-May X Focal & $\beta_{0}^{F}$ & -0.003 & -0.33 & 0.032 & 3.50 & 0.060 & 4.71 \\
Jan-May X Dispute X Focal & $\boldsymbol{\beta}_{\mathbf{1}}^{\boldsymbol{F}}$ & $\mathbf{0 . 0 1 6}$ & $\mathbf{1 . 3 3}$ & $\mathbf{- 0 . 0 4 1}$ & $\mathbf{- 2 . 3 6}$ & $\mathbf{- 0 . 0 6 1}$ & $\mathbf{- 2 . 9 6}$ \\
& & & & & & & \\
Ad spend & $\gamma$ & $5.0 \mathrm{E}-09$ & 2.30 & $2.5 \mathrm{E}-09$ & 0.95 & $1.8 \mathrm{E}-08$ & 3.31 \\
\hline
\end{tabular}

(2) duration

\begin{tabular}{lcrrrrrr} 
& & \multicolumn{1}{c}{ coeff } & t-stat & \multicolumn{1}{c}{ coeff } & t-stat & coeff & t-stat \\
\hline Jan-May & $\beta_{0}$ & 0.044 & 1.55 & 0.059 & 1.94 & 0.112 & 2.79 \\
Jan-May X Dispute & $\beta_{1}$ & 0.025 & 0.52 & -0.005 & -0.11 & 0.008 & 0.14 \\
Jan-May X Focal & $\beta_{0}^{F}$ & 0.003 & 0.03 & 0.260 & 2.97 & 0.807 & 7.22 \\
Jan-May X Dispute X Focal & $\boldsymbol{\beta}_{\mathbf{1}}^{\boldsymbol{F}}$ & $\mathbf{0 . 0 1 5}$ & $\mathbf{0 . 1 0}$ & $\mathbf{- 0 . 3 5 4}$ & $\mathbf{- 2 . 8 6}$ & $\mathbf{- 0 . 5 0 1}$ & $\mathbf{- 2 . 8 5}$ \\
& & & & & & & \\
Ad spend & $\gamma$ & $5.3 \mathrm{E}-08$ & 2.25 & $3.0 \mathrm{E}-08$ & 1.22 & $8.6 \mathrm{E}-08$ & 1.97 \\
\hline
\end{tabular}

(3) pages

\begin{tabular}{llrrrrrr} 
& & coeff & t-stat & coeff & t-stat & coeff & t-stat \\
\hline Jan-May & $\beta_{0}$ & 0.103 & 2.62 & 0.073 & 2.63 & 0.079 & 2.11 \\
Jan-May X Dispute & $\beta_{1}$ & -0.059 & -0.89 & -0.017 & -0.45 & 0.030 & 0.59 \\
Jan-May X Focal & $\beta_{0}^{F}$ & 0.470 & 3.78 & 0.236 & 3.25 & 0.756 & 7.74 \\
Jan-May X Dispute X Focal & $\boldsymbol{\beta}_{\mathbf{1}}^{\boldsymbol{F}}$ & $\mathbf{- 0 . 5 2 0}$ & $\mathbf{- 2 . 4 1}$ & $\mathbf{- 0 . 0 9 1}$ & $\mathbf{- 0 . 8 1}$ & $\mathbf{- 0 . 3 1 2}$ & $\mathbf{- 2 . 0 7}$ \\
Ad spend & $\gamma$ & $4.8 \mathrm{E}-08$ & 1.42 & $2.6 \mathrm{E}-08$ & 1.51 & $1.6 \mathrm{E}-07$ & 4.15 \\
\hline & & & & & & & \\
N obs & 525,300 & & & & & \\
N id & 83,991 & & & & & \\
Fixed effects & id, year, year X focal & & & & \\
Cluster & id & & & & & \\
\hline
\end{tabular}

Note: Tables present diff-in-diff analyses using LonelyPlanet as a control for each of the three dependant variables (1) sites, (2) duration and (3) pages. Each table presents 3 separate regressions run for each of the impacted domains, aa.com, orbitz.com and expedia.com. Jan-May is an indicator for the five months January-May, Dispute is an indicator for the year of the dispute 2011, Focal is an indicator for the impacted domain $\boldsymbol{\beta}_{1}^{\boldsymbol{F}}$ is the relevant treatment effect. 
Table 6: Diff-in-diff analysis using Zero-inflated poisson regression

\begin{tabular}{lllrrrrr}
\hline pages & \multicolumn{3}{c}{ aa.com } & \multicolumn{2}{c}{ orbitz.com } & \multicolumn{2}{c}{ expedia.com } \\
& & coeff & t-stat & coeff & t-stat & coeff & t-stat \\
\hline Jan-May & $\beta_{0}$ & 0.117 & 0.79 & 0.117 & 0.79 & 0.117 & 0.79 \\
Jan-May X Dispute & $\beta_{1}$ & -0.023 & -0.13 & -0.023 & -0.13 & -0.023 & -0.13 \\
Jan-May X Focal & $\beta_{0}^{F}$ & 0.047 & 0.30 & -0.148 & -0.99 & -0.037 & -0.24 \\
Jan-May X Dispute X Focal & $\boldsymbol{\beta}_{\mathbf{1}}^{\boldsymbol{F}}$ & $\mathbf{- 0 . 2 8 7}$ & $\mathbf{- 1 . 3 7}$ & $\mathbf{0 . 1 6 7}$ & $\mathbf{0 . 8 7}$ & $\mathbf{0 . 0 5 3}$ & $\mathbf{0 . 2 8}$ \\
\hline
\end{tabular}

Zero-Inflate

\begin{tabular}{lllrrrrr}
\hline Jan-May & $\zeta_{0}$ & -0.060 & -1.78 & -0.060 & -1.78 & -0.060 & -1.78 \\
Jan-May X Dispute & $\zeta_{1}$ & 0.161 & 2.65 & 0.161 & 2.65 & 0.161 & 2.65 \\
Jan-May X Focal & $\zeta_{0}^{F}$ & 0.064 & 1.67 & -0.107 & -2.96 & -0.063 & -1.76 \\
Jan-May X Dispute X Focal & $\boldsymbol{\zeta}_{1}^{\mathbf{F}}$ & $\mathbf{- 0 . 2 8 4}$ & $\mathbf{- 4 . 1 8}$ & $\mathbf{0 . 0 4 7}$ & $\mathbf{0 . 7 2}$ & $\mathbf{- 0 . 0 7 9}$ & $\mathbf{- 1 . 2 3}$ \\
\hline $\mathrm{N}$ & 525,300 & & & & & \\
N obs & 83,991 & & & & \\
Fixed effects & \multicolumn{2}{c}{ year, year X focal } & & & & \\
Controls & ad spend & & & & \\
Cluster & id & & & & \\
\hline
\end{tabular}

Note: Tables present diff-in-diff analyses using zero-inflated poisson regression. The table presents 3 separate regressions run for each of the impacted domains, aa.com, orbitz.com and expedia.com, run for the dependant variable pages. Jan-May is an indicator for the five months January-May, Dispute is an indicator for the year of the dispute 2011, Focal is an indicator for the impacted domain. $\boldsymbol{\zeta}_{1}^{\boldsymbol{F}}$ is the relevant treatment effect pertaining to a change in zero-visits. A negative $\zeta_{1}^{F}$ implies fewer zero-visits.
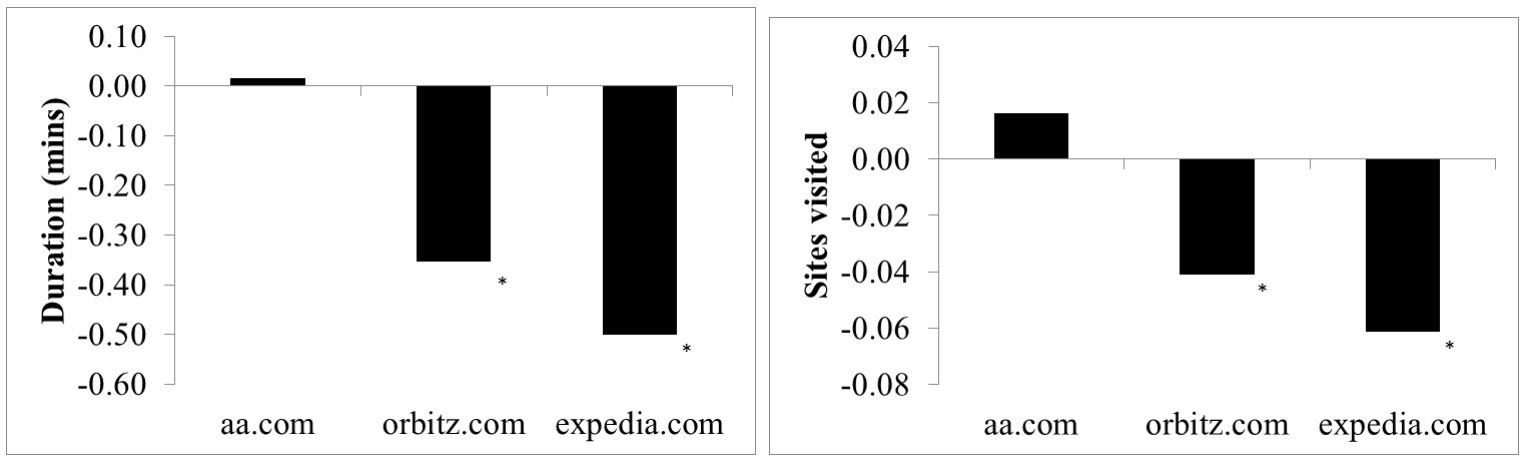

Notes: * significant at the $95 \%$ level.

Figure 4: Duration spent and sites visited decreased for orbitz.com and expedia.com

\subsubsection{Alternative Control Groups}

We now show that our results are robust to a diff-in-diff analysis using direct as well as unlikely competitors as controls, and a simple before-after analysis. We perform these exercises to establish the magnitude and the robustness of the effect. In all subsequent analysis 
after this section, we use Lonely Planet as the control. The results are qualitatively and quantitatively similar when we use the alternative control groups.

\section{Diff-in-diff Analysis with Direct Competitors as Controls}

First, we use direct competitors as controls. Note that while doing so accounts directly for industry-wide trends such an approach measures the net competitive effect of the dispute period on the impacted domains. In other words, if consumers shift their searches from Orbitz to Priceline during the dispute period, we are measuring the decrease in Orbitz relative to the increase in Priceline, relative to the baseline years ${ }^{5}$. We run the same diff-in-diff analysis specified in Equation 1, but with competitors as controls.

\section{Diff-in-Diff Analysis with Unlikely Competitors as Controls}

Second, we estimate the same diff-in-diff regression (Equation 1) as before, but use competitors that are unlikely substitutes to the impacted domains. This helps rule out the possibility of substitution to these domains during the dispute period, while still controlling for industry-wide trends.

For each of the impacted domains, we measure the usage of the other domains to see which domains are least used together. For both Orbitz and Expedia, these domains are Cheapflights, Hotwire, Kayak and Cheapoair. Because not all these domains have airlines as their main focus, we restrict attention to Kayak and Cheapflights that focus on airlines (similar to Orbitz). Moreover, Kayak and Cheapflights are sufficiently different from Orbitz and Expedia in their business models: while users can book directly on Orbitz, Kayak and Cheapflights refer consumers to airline websites, earning a commission for each referral. All these taken together make Kayak and Cheapflights unlikely competitors, but at the same time good controls for any industry-wide trends.

For American, these domains are Alaska Air and Airtran, which are rarely browsed by those users who browse American. However, to make meaningful comparisons, we verify these airlines fly the same routes as American, but are unlikely to be substitutes for American. To do so, we use the DB1B database to determine the degree of competition between airlines. We include as "unlikely competitors" those airlines that fly from a given origin (implying they are present), but have a significantly lower passenger count than American. We find support for Alaska Air as an unlikely competitor: Alaska Air is present in a majority - $76 \%$ - of the airports where American operates. In contrast, jetblue and southwest are present in only $27 \%$

\footnotetext{
${ }^{5}$ In this analysis, we exclude the treated firms from the control group (for example, when analyzing Orbitz, we do not include Expedia and American in the control group). Results are robust to including them in the control.
} 
and $18 \%$ airports respectively. Second, we measure the deviation of all present competitors from American's \% passenger load and find that AlaskaAir has the largest deviation. We first classify an airline as an unlikely competitor if its \% passenger load is less than $90 \%$ of American's (if it were more it would raise the concern of being a close substitute). In $38 \%$ of such cases, AlaskaAir gets classified as American's unlikely competitor, followed by Airtran (28\%), jetblue (16\%) and continental (15\%) with other airlines forming 0\%-2\%. We therefore run the analysis on only those airports where AlaskaAir is classified as an unlikely competitor based on the above analysis.

\section{Before-After Analysis}

Finally, we perform a simple before-after analysis without using any control firms. Assuming that the dispute period (Jan-May 2011) is comparable to the same period in the previous/post years (Jan-May 2010, 2012) in terms of seasonality, trends etc., this estimate tells us how much site visits changed in the year of the dispute relative to the same months in other years. This simple before-after analysis gives us one estimate of the lower bound on the impact of the dispute. This analysis removes bias resulting from comparison with a potentially treated control group, but does not remove any bias that might exist due to a common industry trend during the dispute period in 2011.

We run a regression specified by Equation 3, where $\delta_{1}$ is the treatment effect of the dispute period. This regression includes only the impacted domains (competitor domains are excluded for this simple before-after analysis). For each of the dependant variables - sites, duration and pages - and for each of the impacted domains, we run a separate regression.

$$
\begin{aligned}
y_{i j t} & =\delta_{0} D_{t}+\delta_{1} D_{t} \times \operatorname{Disp}_{Y} \\
& +\alpha_{t Y}+\alpha_{i}+\gamma A d_{j t}+\varepsilon_{i j t}
\end{aligned}
$$

where $y_{i j t}$ is the dependant variable (sites, duration, pages visited on domain $j$ ) by individual $i$ in month $t$. $D_{t}=1$ if $t$ is between January and May, the months relevant to the dispute period in either the treated or untreated years, $D i s p_{Y}=1$ if the months correspond to the year the dispute occurred (2011). $\alpha_{t Y}$ and $\alpha_{i}$ are year and individual fixed-effects respectively.

Table 7 presents the results of the (1) diff-in-diff analysis using direct competitors as controls, (2) diff-in-diff analysis using unlikely competitors as controls, and (3) simple beforeafter analysis. The results show that across all three specifications, Orbitz and Expedia experience a significant decline in their browsing behavior during the dispute period. Moreover, the magnitude of the drop is identical to the findings in the main analysis: 0.04 site 
visits for Orbitz, 0.05 site visits for Expedia. American sees an increase in all three specifications, but the increase is statistically significant only in the diff-in-diff analysis using direct competitors. For brevity we present results for only the dependant variable sites here.

Table 7: Site visits to aa.com unchanged, to orbitz.com and expedia.com drop during the dispute period: Results robust to three different analyses

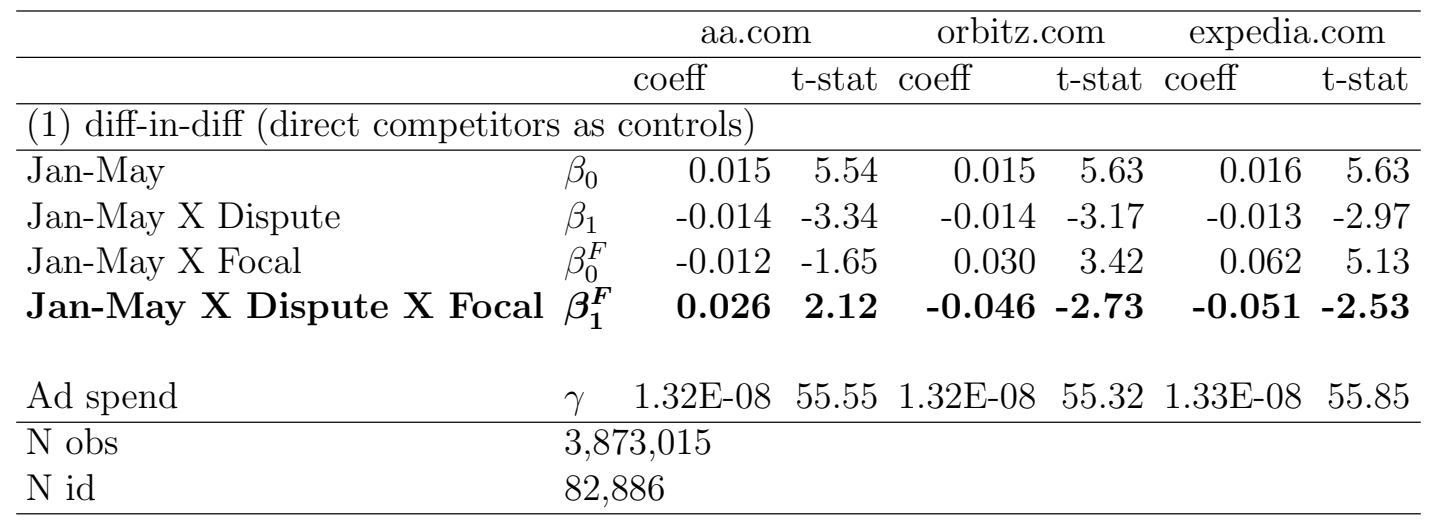

(2) diff-in-diff (unlikely competitors as controls)

\begin{tabular}{llrrrrrr}
\hline Jan-May & $\beta_{0}$ & 0.007 & 1.30 & 0.012 & 3.23 & 0.012 & 2.91 \\
Jan-May X Dispute & $\beta_{1}$ & -0.001 & -0.09 & -0.016 & -2.38 & -0.015 & -2.05 \\
Jan-May X Focal & $\beta_{0}^{F}$ & -0.019 & -1.13 & 0.034 & 3.76 & 0.056 & 4.62 \\
Jan-May X Dispute X Focal & $\boldsymbol{\beta}_{\mathbf{1}}^{\boldsymbol{F}}$ & $\mathbf{0 . 0 4 4}$ & $\mathbf{1 . 9 1}$ & $\mathbf{- 0 . 0 6 1}$ & $\mathbf{- 3 . 5 6}$ & $\mathbf{- 0 . 0 5 9}$ & $\mathbf{- 2 . 9 3}$ \\
& & & & & & & \\
Ad spend & $\gamma$ & $4.56 \mathrm{E}-09$ & 1.18 & $2.94 \mathrm{E}-08$ & 28.68 & $3.72 \mathrm{E}-08$ & 34.31 \\
\hline N obs & & 141,586 & & 774,603 & & 774,603 & \\
$\mathrm{~N}$ id & & 22,702 & \multicolumn{2}{c}{82,886} & & 82,886 & \\
\hline
\end{tabular}

(3) before-after analysis

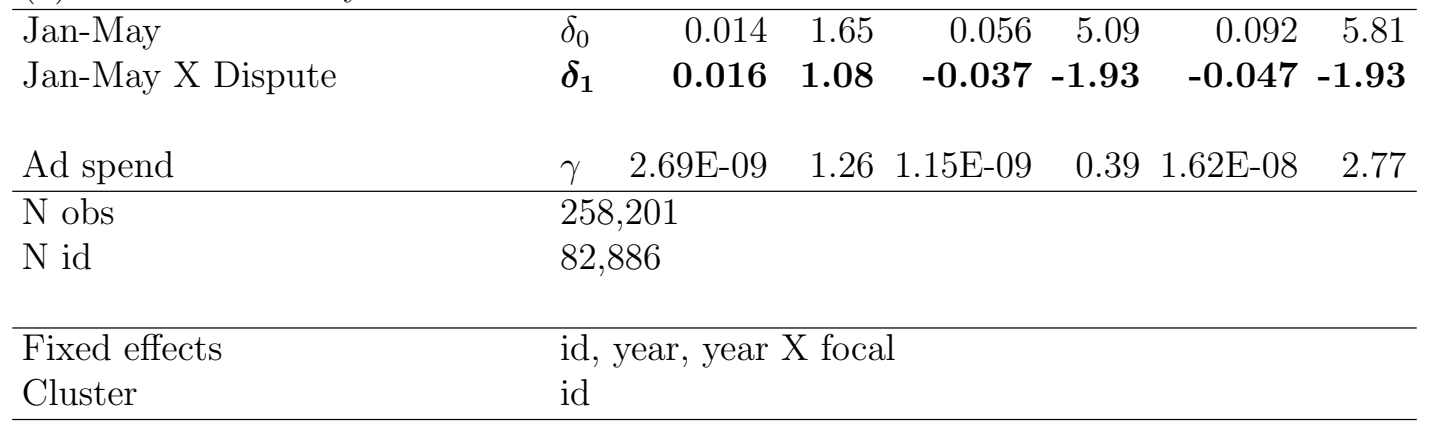

Note: (1) presents a diff-in-diff analysis using direct competitors as controls. (2) presents a diff-in-diff analysis using unlikely competitors as controls: Alaska Air on routes where it operates and is likely to be an unlikely comeptitor for American; and Kayak and Cheapflights for Orbitz and Expedia. (3) presents a before-after analysis for visits to the treated domains. Each table presents 3 separate regressions run for the dependant variables sites. $\boldsymbol{\beta}_{\mathbf{1}}^{\boldsymbol{F}}$ in (1) and (2), and $\boldsymbol{\delta}_{\mathbf{1}}$ in (3) are the relevant treatment effects. 


\subsubsection{Robustness Checks}

In the main analysis, we assume all searches prior to the final visit/transaction are relevant. We now verify if our results are robust to using much shorter windows of search: 1 month and 2 months, i.e., we only use visits to travel domains up to 1 month and 2 months before the last visit. Tables 26 and 27 in Appendix B report the relevant estimates. We find that our results are robust to these specifications; specifically, we see Orbitz and Expedia are negatively impacted (even more so) during the dispute period.

Next, we test if our results are robust to removing outliers in the data. The data contains instances when the number of pages viewed in a single session exceeds 100 and the duration spent exceeds 1 hour. In such instances a browsing window could have remained open for too long without active search. We therefore remove those sessions that exceed the 99th percentile in the data: more than 51 page views and 61 minutes for a single session. The results reported in Table 28 of Appendix B are fairly identical to our main results in Table 5 .

Finally, Expedia brought back American fares after 3 months. To verify if the results are robust to this smaller time window, Table 29 in Appendix B shows this change for this 3-month period. As can be seen, the effects are similar.

\subsubsection{Total Searches}

In this section, we test to see if the dispute had an impact on the total number of searches conducted by a consumer: do consumers augment their searches causing an increase in total sites visited, do they drop a few websites causing a decrease, or does the total search intensity remain unchanged. To conduct this analysis, we include all months (per individual) irrespective of whether a search was conducted. We then evaluate 1) changes in the total intensity of search, and 2) whether the treated firms exhibit the same patterns documented thus far.

We find, across all outcome measures, individuals search less during the dispute period. To understand if this is driven by individuals searching less at airlines, or aggregators, or both, we split the outcome measures by searches at each group. Table 8 reports the results for Total Searches, Searches at Aggregators, and Searches at Airlines. We find that most of the decline in searches comes from a drop in aggregator usage. Airline usage is largely unchanged with the exception of pages visited which sees a drop. Taken together these results indicate that without comprehensive aggregators, aggregators stand to lose, and perhaps to some extent airlines as well because consumers might now find poorer matches. However, to conclusively state if these changes are economically meaningful we rely on the demand 
analysis conducted in Section 4.3.

We further find, similar to our main analysis, that search patterns on this expanded dataset indicate a decline in site visits at Orbitz and Expedia (Table 9). Moreover, as a percentage change, these numbers are fairly identical to our main analysis: $13.7 \%$ for Orbitz and $12.9 \%$ for Expedia.

Table 8: Total Searches

\begin{tabular}{|c|c|c|c|c|c|}
\hline \multirow[t]{2}{*}{ (1) All } & \multicolumn{3}{|r|}{ duration } & \multicolumn{2}{|c|}{ pages } \\
\hline & coeff & t-stat & t-stat & coeff & t-stat \\
\hline Jan-May & 0.126 & 13.09 & 0.98711 .56 & 1.182 & 14.20 \\
\hline Jan-May X Dispute & $\delta_{1}-0.063$ & -3.98 & $-0.473-3.45$ & -0.710 & -4.90 \\
\hline \multirow[t]{2}{*}{ (2) Aggregators } & \multicolumn{2}{|c|}{ sites } & duration & \multicolumn{2}{|c|}{ pages } \\
\hline & coeff & t-stat & t-stat & coeff & t-stat \\
\hline Jan-May & 0.096 & 13.88 & $0.763 \quad 12.03$ & 0.777 & 13.77 \\
\hline Jan-May X Dispute & $\delta_{1}-0.063$ & -5.53 & $-0.467-4.76$ & -0.362 & -4.34 \\
\hline \multirow[t]{2}{*}{ (3) Airlines } & \multicolumn{2}{|c|}{ sites } & duration & \multicolumn{2}{|c|}{ pages } \\
\hline & coeff & t-stat & t-stat & coeff & t-stat \\
\hline Jan-May & 0.030 & 6.24 & 0.224 & 0.405 & 7.85 \\
\hline Jan-May X Dispute & $\begin{array}{ll}\delta_{1} & 0.001\end{array}$ & 0.11 & $-0.007-0.09$ & -0.348 & -3.26 \\
\hline N obs & $1,267,152$ & & & & \\
\hline $\mathrm{N}$ id & 82,886 & & & & \\
\hline Fixed effects & id, year & & & & \\
\hline Controls & Ad spend & & & & \\
\hline Cluster & id & & & & \\
\hline
\end{tabular}

Note: Table presents a diff analysis across (1) all domains, (2) all aggregators, and (3) all airlines on the dependant measures total sites, total duration spent and total pages. The data is expanded to include months of no search. $\boldsymbol{\delta}_{\mathbf{1}}$ is the relevant treatment effect. 
Table 9: Diff-in-diff analysis including no-search months

\begin{tabular}{|c|c|c|c|c|c|c|}
\hline & \multicolumn{2}{|c|}{ aa.com } & \multicolumn{2}{|c|}{ orbitz.com } & \multicolumn{2}{|c|}{ expedia.com } \\
\hline & coeff & t-stat & coeff & t-stat & coeff & t-stat \\
\hline Jan-May & $\begin{array}{ll}\beta_{0} & 0.001\end{array}$ & 4.74 & 0.001 & 4.74 & 0.001 & 4.75 \\
\hline Jan-May X Dispute & $\beta_{1}-0.001$ & -3.47 & -0.001 & -3.47 & -0.001 & -3.48 \\
\hline Jan-May X Focal & $\beta_{0}^{F} \quad 0.004$ & 2.66 & 0.014 & 7.33 & 0.027 & 9.67 \\
\hline Jan-May X Dispute X Focal & $\beta_{1}^{F} \quad 0.002$ & 0.87 & -0.011 & -2.94 & -0.020 & -4.36 \\
\hline $\mathrm{N}$ obs & $2,563,728$ & & & & & \\
\hline $\mathrm{N}$ id & 83,991 & & & & & \\
\hline Fixed effects & id, Year, Y & ear X & Focal & & & \\
\hline Controls & Ad spend & & & & & \\
\hline Cluster & id & & & & & \\
\hline
\end{tabular}

\subsection{Heterogeneity in Browsing behavior}

The literature on manufacturer-retailer interactions has two main theoretical predictions that relate to competition and loyalty. On competition, the literature (e.g., O'Brien and Shaffer 1997, Kadiyali et al 2000) suggests increased manufacturer competition makes for higher retailer market power. On loyalty, the literature suggests loyalty can relieve competition thus giving the manufacturer more power (see Ailawadi et al (2010) for a review of the theoretical work around this). Our setting allows us to empirically test these two theoretical predictions.

We operationalize manufacturer competition using the localized nature of airline competition that provides variation across airports ${ }^{6}$. We expect that in airports that face more competition (and have a strong American presence) the aggregators Expedia and Orbitz will not be significantly impacted during the dispute, i.e. the retailer has more power.

We operationalize loyalty to aggregators/airlines based on consumers' usage of aggregators/airlines. We expect the biggest change to occur among consumers who use multiple aggregators, i.e., users who are least loyal to Expedia/Orbitz.

In addition, we also expect that airports with no American presence will see little impact of the dispute. Similarly, airports where American is the most important airline will also see little impact of the dispute. Such users might be fairly well informed of American's offerings and primarily use aggregators to learn about competing airlines' offerings, which Orbitz and Expedia still offer. We test all three dimensions of heterogeneity (American presence, competition, loyalty) below.

\footnotetext{
${ }^{6}$ We thank the Editor for this insight
} 


\subsubsection{Airports with No American Presence, High American Presence vs. the rest}

We use the Airline Origin and Destination Survey (DB1B) database to infer the importance of each airline to an airport. We create an importance score, $\mathrm{imp}_{m j}$, for each airline $j$-airport $m$ combination as follows:

$$
\operatorname{imp}_{m j}=\frac{d_{m j}}{\sum_{j} d_{m j}}
$$

where $d_{m j}$ is the total number of passengers who flew from origin airport $m$ in airline $j$ across the years 2010-2012 and $\sum_{j} d_{m j}$ sums across all passengers for that airport across all top airlines.

The comScore data provides us with the zipcode of each individual user in the panel. From this, we infer the closest airport to each user, using the Euclidean distance between every airport and the center of the user's zipcode as our distance measure. We then merge the importance measure to the comScore data to determine if a consumer lives near an airport where American is absent or prominent.

We subset airports based on relative presence of American airlines: (1) those where American has no presence, i.e., $i m p_{m, A A}=0$. We consider the nearest as well as the second nearest airport to a consumer's zipcode if that second airport is within 50 miles, to allow for substitution between nearby airports. We also add the constraint that the airport have atleast one major airline operating, to avoid considering small regional airports where consumers might travel farther (for example, AHN is a regional airport with no major airlines, but a consumer can easily drive to ATL which is a $1.5 \mathrm{hr} / 78$ mile drive away) (2) those where American has a high presence, i.e., it is one of the top two airlines as measured by passengers served at that airport, and (3) those where American is neither absent nor most important ${ }^{7}$. We expect the impact of the dispute to be strongest for the last subset (3), where American is neither absent nor most important, because this is where the role of aggregators is most relevant.

Table 10 presents the results for each subset, as well as the results for the entire dataset. As expected, we do not see any effect on the treated firms at airports where American has no presence. Similarly, consumers living near airports with high American presence do not

\footnotetext{
${ }^{7}$ Airports with no American presence are typically small with an average yearly passenger count of 81 per airport. Airports include Adak Regional, Mid Delta Regional and Frank Wiley Field. Those that have high American presence include all of American's hubs (LAX, ORD, DFW, LGA, JFK and MIA) as well as many smaller regional airports like Waco Regional and Tyler Pounds Regional where American is the prominent player. Airports that are neither include big airports like Atlanta where Delta is the most important player and San Diego where Southwest is the most important player along with many smaller airports.
} 
change their behavior. This is because they likely know about American and use aggregators to search for other airlines (such as United) for whom the aggregators are still useful. The last subset (3) is where we find the strongest effect of the dispute, supporting our hypothesis. Consumers who live close to an airport where another airline is prominent (e.g., United) drop their usage of Orbitz and Expedia. Such consumers might not be well informed of American's fares, and therefore might use aggregators to conduct a comprehensive search of their options. However, now that Orbitz and Expedia are not as informative, they are less useful. In fact, comparing the estimates of this subset to that using all the data, the results are stronger both in significance as well as magnitude.

We also repeat this exercise using a simple diff analysis, without using competitors to see if the direction of the results hold. Table 30 in Appendix B presents the results of this simple diff specification, confirming the direction of the effect.

\subsubsection{Competitive airports}

Per the theoretical literature, we expect that in airports that face more competition (and have a strong American presence) the aggregators Expedia and Orbitz will not be significantly impacted during the dispute, i.e. the retailer has more power. We define each airport's competitiveness by their $h h i$ measured as $h h i_{m}=\sum\left(\frac{d_{m j}}{\sum_{j} d_{m j}}\right)^{2}$ where $d_{m j}$ is the passenger demand for airport $m$ and airline $j$. We define a high competition airport for American as one where 1) $h h i<0.18$ which is the 75 th percentile across all airports (the mean $h h i$ is 0.14). and 2) American has a significant presence, i.e., it forms atleast $10 \%$ of the passenger demand at that airport. We add this restriction because we are not interested in high competition airports where the competition is between two un-treated airlines. We also consider American's hubs: American has 6 hubs all of which are fairly competitive. Finally, we identify cities that have multiple hubs at different airports atleast one of which is an American hub. As an example, Chicago has ORD (United, American), MDW (Southwest) and MKE (Southwest and Airtran). Therefore, we include consumers who live near all three airports and not just those who live near ORD.

We combine all three measures of competition: airports that are hubs for multiple airlines, cities that have multiple hubs at different airports, and airports that have high competition. Airports that satisfy all three criteria are LAX, LGA and ORD. On the other extreme, we classify as low competition, airports that are not hubs for multiple airlines and are not in cities that have multiple hubs, and have low competition as defined by $h h i \geq 0.18$. In addition, we exclude airports with no American presence or high American presence to ensure we analyze areas where the aggregator is needed (per the analysis in Section 4.2.1 the aggregator's function is minimal in these two extremes of American's presence). 81 airports 
satisfy this criteria and are included in the "low competition" analysis. Tables 11 and 31 show the diff-in-diff analysis as well as simple diff analysis. These tables show that the retailers (Orbitz and Expedia) are not impacted in areas where there is high competition. Finally, we note that our data does not have enough power to do a D-D-D analysis between areas with low competition and the rest.

\subsubsection{Loyalty: Multiple vs single use of aggregators/airlines}

Section 3 documents the difference in consumers' usage behavior of aggregators and airlines, with some consumers visiting only 1 aggregator and others visiting multiple aggregators. Given this difference in usage behavior, we conduct the analysis separately on these different groups. We expect those who use multiple aggregators will see the biggest change in behavior. Table 12 validates our hypothesis. Column (3) suggests those who use Expedia combined with other aggregators during search, are the ones who stop using Expedia during the dispute. Column (1) suggests those who use only Expedia to inform their search do not change their behavior during the dispute period. A similar pattern holds for Orbitz as well, seen in Table 13. This analysis shows that competition in the aggregator space matters: the decline is strongest among users who view aggregators as close substitutes.

We repeat the same exercise, but now as defined by consumers' usage of American, reported in Table 14. Column (1) of Table 14 suggests those loyal to American increase their browsing on American during the dispute period. This pattern does not replicate for those users not loyal towards American. Examining the group of loyal users further, we split them into those who use aggregators vs. those who do not. We find the increase in visits to American is driven by those who use aggregators (Table 15). We confirm this is driven by users who visit Orbitz and Expedia, and not just any aggregator. We therefore believe this pattern occurs because information is unavailable on two of the aggregators, such users come to American more often. As a placebo check, we repeat the same exercise as defined by consumers' usage of Delta and do not find such a pattern (Table 16).

Note that while the above grouping is indicative of users' loyalty, it is also contaminated by the treatment (for example, American might have users that are more loyal during the dispute because of the dispute). Therefore, for all of these analyses, we expand the dataset to include months of no-search as well to allow for changes in the extensive margin thus mitigating such a concern. 
Table 10: Site visits for consumers living near airports with varying degrees of American presence: diff-in-diff

\section{(1) No American Airlines serving nearby airports}

\begin{tabular}{llllrrrrr} 
& \multicolumn{3}{c}{ aa.com } & \multicolumn{3}{c}{ orbitz.com } & \multicolumn{3}{c}{ expedia.com } \\
& & coeff & \multicolumn{1}{c}{ t-stat } & coeff & t-stat & coeff & t-stat \\
\hline Jan-May & $\beta_{0}$ & -0.007 & -0.51 & 0.057 & 1.98 & 0.068 & 1.23 \\
Jan-May X Dispute & $\beta_{1}$ & -0.015 & -0.47 & -0.044 & -0.92 & -0.056 & -0.81 \\
Jan-May X Domain & $\beta_{0}^{F}$ & -0.016 & -0.5 & 0.028 & 0.26 & 0.213 & 0.84 \\
Dispute X Treatment X Domain & $\boldsymbol{\beta}_{\mathbf{1}}^{\boldsymbol{F}}$ & $\mathbf{0 . 0 2 7}$ & $\mathbf{0 . 3 8}$ & $\mathbf{0 . 0 4 9}$ & $\mathbf{0 . 3 6}$ & $\mathbf{- 0 . 1 6 7}$ & $\mathbf{- 0 . 7 4}$ \\
\hline N obs & 2,520 & & & & & & \\
N & 485 & & & & & & \\
\hline
\end{tabular}

(2) American is most important airline in nearest airport

\begin{tabular}{llrrrrrrr} 
& & \multicolumn{3}{c}{ aa.com } & \multicolumn{3}{c}{ orbitz.com } & \multicolumn{3}{c}{ expedia.com } \\
& & coeff & \multicolumn{1}{c}{ t-stat } & coeff & t-stat & coeff & t-stat \\
\hline Jan-May & $\beta_{0}$ & 0.017 & 2.48 & 0.016 & 2.1 & 0.015 & 1.97 \\
Jan-May X Dispute & $\beta_{1}$ & -0.014 & -1.3 & -0.008 & -0.69 & 0.002 & 0.16 \\
Jan-May X Domain & $\beta_{0}^{F}$ & 0.005 & 0.25 & -0.002 & -0.09 & 0.023 & 0.95 \\
Dispute X Treatment X Domain & $\boldsymbol{\beta}_{\mathbf{1}}^{\boldsymbol{F}}$ & $\mathbf{- 0 . 0 0 4}$ & $\mathbf{- 0 . 1 3}$ & $\mathbf{0 . 0 4 5}$ & $\mathbf{1 . 0 2}$ & $\mathbf{- 0 . 0 1 4}$ & $\mathbf{- 0 . 3 9}$ \\
\hline N obs & 126,066 & & & & & & & \\
N & 20,782 & & & & & & \\
\hline
\end{tabular}

(3) Airport is neither American-absent or American-important

\begin{tabular}{|c|c|c|c|c|c|c|}
\hline & \multicolumn{2}{|c|}{ aa.com } & \multicolumn{4}{|c|}{ orbitz.com expedia.com } \\
\hline & coeff & t-stat & coeff & t-stat & coeff & t-stat \\
\hline Jan-May & 0.007 & 2.56 & 0.011 & 2.93 & 0.014 & 2.78 \\
\hline Jan-May X Dispute & -0.001 & -0.21 & 0.002 & 0.28 & 0.008 & 0.82 \\
\hline Jan-May X Domain & -0.004 & -0.52 & 0.047 & 5.17 & 0.076 & 5.23 \\
\hline Dispute X Treatment X Domain & 0.022 & 1.65 & -0.071 & -3.97 & -0.080 & -3.21 \\
\hline $\mathrm{N}$ obs & 394,000 & & & & & \\
\hline $\mathrm{N}$ & 62,351 & & & & & \\
\hline \multirow[t]{2}{*}{ All data } & & aa.com & \multicolumn{2}{|c|}{ orbitz.com } & \multicolumn{2}{|c|}{ expedia.com } \\
\hline & coeff & t-stat & coeff & t-stat & coeff & t-stat \\
\hline Jan-May & 0.010 & 3.58 & 0.012 & 3.7 & 0.015 & 3.4 \\
\hline Jan-May X Dispute & -0.004 & -0.79 & 0.000 & -0.06 & 0.006 & 0.75 \\
\hline Jan-May X Domain & -0.003 & -0.35 & 0.035 & 3.96 & 0.064 & 5.11 \\
\hline Dispute X Treatment X Domain & 0.016 & 1.33 & -0.043 & -2.49 & -0.065 & -3.12 \\
\hline $\mathrm{N}$ obs & 523,054 & & & & & \\
\hline $\mathrm{N}$ & 83,522 & & & & & \\
\hline Fixed effects & id, year, year $\mathrm{X}$ fo & cal & & & & \\
\hline Controls & Ad spend & & & & & \\
\hline Cluster & id & & & & & \\
\hline
\end{tabular}

Note: This table presents a diff-in-diff analysis, with LonelyPlanet visits as the control, for visits to the treated domains for three subsets of the data, 1) airports with No American presence, 2) Airports where American is the most important airline and 3) the rest. The hypothesis is that we will see the strongest effect of the dispute in susbet (3), because this is where the role of aggregators is most relevant. For reference, analysis using All data is also presented. A few individuals do not have an associated zipcode and therefore drop out of this analysis. $\boldsymbol{\beta}_{\mathbf{1}}^{\boldsymbol{F}}$ is the relevant treatment effect. 
Table 11: Site visits for consumers living near airports with varying degrees of competition: diff-in-diff

\begin{tabular}{|c|c|c|c|c|c|c|c|}
\hline \multicolumn{8}{|l|}{ (1) High competition airports } \\
\hline & & \multicolumn{2}{|c|}{ aa.com } & \multicolumn{2}{|c|}{ orbitz.com } & \multicolumn{2}{|c|}{ expedia.com } \\
\hline & & coeff & t-stat & coeff & t-stat & coeff & t-stat \\
\hline Dispute & $\beta_{0}$ & 0.016 & 1.01 & 0.015 & 0.69 & 0.030 & 1.62 \\
\hline Dispute X Treatment & $\beta_{1}$ & 0.007 & 0.32 & 0.001 & 0.05 & -0.018 & -0.7 \\
\hline Dispute X Domain & $\beta_{0}^{F}$ & 0.058 & 1.11 & 0.045 & 0.64 & 0.043 & 0.69 \\
\hline Dispute X Treatment X Domain & $\boldsymbol{\beta}_{1}^{F}$ & -0.042 & -0.62 & -0.078 & -0.91 & -0.059 & -0.66 \\
\hline Ad spend & $\gamma$ & $3.5 \mathrm{E}-08$ & 1.33 & $-5.4 \mathrm{E}-09$ & -0.32 & $-6.7 \mathrm{E}-09$ & -0.29 \\
\hline N obs & 29,6 & & & & & & \\
\hline $\mathrm{N}$ & 4,20 & & & & & & \\
\hline
\end{tabular}

(2) Low competition airports

\begin{tabular}{llrrrrrrr} 
& \multicolumn{3}{c}{ aa.com } & \multicolumn{2}{c}{ orbitz.com } & \multicolumn{2}{c}{ expedia.com } \\
& \multicolumn{2}{c}{ coeff } & t-stat & coeff & t-stat & coeff & t-stat \\
\hline Dispute & $\beta_{0}$ & 0.002 & 0.51 & 0.002 & 0.2 & 0.011 & 1.37 \\
Dispute X Treatment & $\beta_{1}$ & 0.013 & 1.64 & 0.015 & 0.96 & 0.021 & 1.22 \\
Dispute X Domain & $\beta_{0}^{F}$ & 0.009 & 0.72 & 0.056 & 3.91 & 0.081 & 4.18 \\
Dispute X Treatment X Domain & $\boldsymbol{\beta}_{\mathbf{1}}^{\boldsymbol{F}}$ & $\mathbf{0 . 0 0 8}$ & $\mathbf{0 . 3 6}$ & $\mathbf{- 0 . 0 9 6}$ & $\mathbf{- 2 . 4 7}$ & $\mathbf{- 0 . 1 1 4}$ & $\mathbf{- 2 . 4 4}$ \\
& & & & & & & \\
Ad spend & $\gamma$ & $6.1 \mathrm{E}-09$ & 2.07 & $1.9 \mathrm{E}-09$ & 0.52 & $1.6 \mathrm{E}-08$ & 2.02 \\
\hline $\mathrm{N}$ obs & 129,342 & & & & & \\
$\mathrm{~N}$ & 19,777 & & & & & \\
\hline
\end{tabular}

Table 12: Diff-in-diff analysis by varying degrees of Expedia's market power

\begin{tabular}{|c|c|c|c|c|}
\hline & (1) & $(2)$ & \multicolumn{2}{|c|}{ (3) } \\
\hline & Only Expedia & $\begin{array}{l}\text { Expedia and } \\
1-2 \text { others }\end{array}$ & $\begin{array}{r}\text { Expedia } \\
\text { than } 2\end{array}$ & $\begin{array}{l}\text { more } \\
\text { hers }\end{array}$ \\
\hline & coeff t-stat & coeff t-stat & coeff & t-stat \\
\hline Jan-May & 0.000 & 0.001 & 0.002 & 3.91 \\
\hline Jan-May X Dispute & $-0.001-1.15$ & $-0.002-1.64$ & -0.002 & -2.10 \\
\hline Jan-May X Expedia & 0.028 & 0.020 & 0.063 & 9.56 \\
\hline Jan-May X Dispute X Exp. $\beta_{1}^{F}$ & $-0.010-0.67$ & $-0.023-1.52$ & -0.041 & -3.82 \\
\hline Ad spend & $1.3 \mathrm{E}-08$ & $1.5 \mathrm{E}-08$ & $5.2 \mathrm{E}-09$ & 1.79 \\
\hline $\mathrm{N}$ obs & 276,840 & 472,536 & 822,696 & \\
\hline $\mathrm{N}$ & 10,746 & 16,522 & 22,301 & \\
\hline
\end{tabular}

Note: Table presents 3 separate regressions for each of the three groups of users: (1) those who browse only Expedia and no other aggregator, (2) those who browse Expedia and 1-2 other aggregators, and (3) those who browse Expedia and more than 2 other aggregators. The last group are the least loyal to Expedia, and we expect these users to drop their site visits to Expedia. 
Table 13: Diff-in-diff analysis by varying degrees of Orbitz's market power

\begin{tabular}{|c|c|c|c|c|c|c|c|}
\hline & \multicolumn{2}{|c|}{ (1) } & \multicolumn{2}{|c|}{$(2)$} & \multicolumn{2}{|c|}{ (3) } \\
\hline & & \multicolumn{2}{|c|}{ Only Orbitz } & \multicolumn{2}{|c|}{$\begin{array}{l}\text { Orbitz and } \\
1-2 \text { others }\end{array}$} & \multicolumn{2}{|c|}{$\begin{array}{l}\text { Orbitz and more } \\
\text { than } 2 \text { others }\end{array}$} \\
\hline & & coeff & t-stat & coeff & t-stat & coeff & t-stat \\
\hline Jan-May & $\beta_{0}$ & 0.001 & 1.54 & 0.002 & 1.88 & 0.003 & 4.31 \\
\hline Jan-May X Dispute & $\beta_{1}$ & -0.001 & -0.91 & -0.002 & -1.27 & -0.002 & -1.89 \\
\hline Jan-May X Orbitz & $\beta_{0}^{F}$ & 0.017 & 2.21 & 0.010 & 1.06 & 0.046 & 7.73 \\
\hline Jan-May X Dispute X Orbitz & $\beta_{1}^{F}$ & 0.006 & 0.40 & 0.003 & 0.12 & -0.038 & -3.95 \\
\hline Ad spend & & $-5.3 \mathrm{E}-10$ & -0.32 & $2.3 \mathrm{E}-09$ & 1.20 & $-1.3 \mathrm{E}-09$ & -0.73 \\
\hline N obs & & 71,016 & & 244,464 & & 699,360 & \\
\hline $\mathrm{N}$ & & 2,669 & & 8,403 & & 18,563 & \\
\hline
\end{tabular}

Note: Table presents 3 separate regressions for each of the three groups of users: (1) those who browse only Orbitz and no other aggregator, (2) those who browse Orbitz and 1-2 other aggregators, and (3) those who browse Orbitz and more than 2 other aggregators. The last group are the least loyal to Orbitz, and we expect these users to drop their site visits to Orbitz.

Table 14: Diff-in-diff analysis by varying degrees of AA's market power

\begin{tabular}{|c|c|c|c|c|c|c|}
\hline & \multicolumn{2}{|c|}{ (1) } & \multicolumn{2}{|c|}{$(2)$} & \multicolumn{2}{|c|}{ (3) } \\
\hline & Only & $\mathrm{AA}$ & $\begin{array}{r}\mathrm{AA} \\
1-2 \text { ot }\end{array}$ & $\begin{array}{l}\text { and } \\
\text { thers }\end{array}$ & $\begin{array}{l}\mathrm{AA} \text { and } \\
\text { than } 2\end{array}$ & $\begin{array}{l}\text { d more } \\
\text { others }\end{array}$ \\
\hline & coeff & t-stat & coeff & t-stat & coeff & t-stat \\
\hline Jan-May & 0.001 & 1.23 & 0.002 & 2.14 & 0.002 & 1.54 \\
\hline Jan-May X Dispute & -0.006 & -3.06 & 0.000 & -0.22 & -0.002 & -1.19 \\
\hline Jan-May X AA & 0.004 & 0.25 & 0.031 & 2.93 & 0.022 & 2.21 \\
\hline Jan-May X Dispute X AA $\beta_{1}^{F}$ & 0.070 & 2.89 & -0.017 & -0.91 & 0.000 & -0.02 \\
\hline Ad spend & $-1.3 \mathrm{E}-09$ & -0.46 & $-5.4 \mathrm{E}-09$ & -1.60 & $3.8 \mathrm{E}-10$ & 0.10 \\
\hline $\mathrm{N}$ obs & 94,608 & & 219,792 & & 266,496 & \\
\hline $\mathrm{N}$ & 3,603 & & 6,478 & & 5,121 & \\
\hline
\end{tabular}

Note: Table presents 3 separate regressions for each of the three groups of users: (1) those who browse only AA and no other airlines, (2) those who browse AA and 1-2 other airlines, and (3) those who browse AA and more than 2 other airlines. 
Table 15: Diff-in-diff analysis for those who browse only AA: by varying degrees of aggregator usage

\begin{tabular}{lcrrrr}
\hline & \multicolumn{5}{c}{ Only AA } \\
& \multicolumn{4}{c}{ No aggregator } & \multicolumn{2}{c}{ Use aggregators } \\
& \multicolumn{2}{c}{ coeff } & t-stat & coeff & t-stat \\
\hline Jan-May & $\beta_{0}$ & N/A & N/A & 0.002 & 1.28 \\
Jan-May X Dispute & $\beta_{1}$ & N/A & N/A & -0.008 & -3.09 \\
Jan-May X AA & $\beta_{0}^{F}$ & 0.042 & 1.93 & -0.011 & -0.52 \\
Jan-May X Dispute X AA $\boldsymbol{\beta}_{\mathbf{1}}^{\boldsymbol{F}}$ & $\mathbf{0 . 0 0 1}$ & $\mathbf{0 . 0 3}$ & $\mathbf{0 . 1 0 1}$ & $\mathbf{3 . 1 3}$ \\
& & & & & \\
Ad spend & & $-5.4 \mathrm{E}-09$ & -1.60 & $3.8 \mathrm{E}-10$ & 0.10 \\
\hline N obs & & 28,704 & & 65,904 & \\
N & & 1,168 & & 2,435 & \\
\hline
\end{tabular}

Note: Table presents 2 separate regressions for the subset of users who browse only American and no other airline. This group is further susbet into those who never use aggregators and those who use atleast one aggregator.

Table 16: Placebo check: Diff-in-diff analysis by varying degrees of Delta's market power

\begin{tabular}{|c|c|c|c|c|c|c|}
\hline & \multicolumn{2}{|c|}{ Only Delta } & \multicolumn{2}{|c|}{$\begin{array}{l}\text { Delta and } \\
1-2 \text { others }\end{array}$} & \multicolumn{2}{|c|}{$\begin{array}{c}\text { Delta and more } \\
\text { than } 2 \text { others }\end{array}$} \\
\hline & coeff & t-stat & coeff & t-stat & coeff & t-stat \\
\hline Jan-May & 0.002 & 1.96 & 0.002 & 2.56 & 0.001 & 1.03 \\
\hline Jan-May X Dispute & -0.002 & -1.38 & -0.001 & -0.77 & -0.001 & -0.40 \\
\hline Jan-May X Delta & -0.013 & -0.73 & 0.021 & 2.42 & 0.007 & 0.62 \\
\hline Jan-May X Dispute X Delta $\beta_{1}^{F}$ & 0.025 & 0.90 & -0.029 & -1.69 & 0.021 & 1.28 \\
\hline Ad spend & $-2.2 \mathrm{E}-09$ & -1.57 & $-1.7 \mathrm{E}-09$ & -1.80 & $8.9 \mathrm{E}-10$ & 0.90 \\
\hline $\mathrm{N}$ obs & 113,016 & & 249,936 & & 285,264 & \\
\hline $\mathrm{N}$ & 4,282 & & 7,287 & & 5,418 & \\
\hline
\end{tabular}

Note: Table presents 3 separate regressions for each of the three groups of users: (1) those who browse only Delta and no other airlines, (2) those who browse Delta and 1-2 other airlines, and (3) those who browse Delta and more than 2 other airlines.

\subsection{Purchase behavior on aggregators and airlines}

We now explore whether the dispute period had an impact on purchases. We first use the comScore data, which track transactions at the domain level, to measure changes in Orbitz's and American's purchases. Note that because comScore tracks only online transactions, we might miss any airline sales that occurred through other channels such as offline travel agents or over the phone. To account for all sales, we therefore use the DB1B database to measure the total impact of the dispute on American's sales. 
The comScore data also does not have an accurate measure of prices. Prices are unobserved if there was no transaction. Although prices can be constructed from publicly available data, we do not know the (potential) destination of the consumer. Therefore, our analysis in section 4.3.2 which uses the DB1B database and which has prices at the quarterly level for every origin-destination pair and carrier will help us further account for prices in the demand estimation.

\subsubsection{Purchases: comScore data}

We first expand the data to include the outside option. We do so to allow for the fact that users might use other channels (e.g. offline travel agents) to make their airline bookings or choose not to participate in the airline market. We include both 1) all months of search as potential months when a consumer could have purchased a ticket and 2) only the last month of search as a potential month of purchase. The latter option is closer to reality because those who buy always purchase on the last month of browsing, so one can assume safely that for all no purchases, they would have purchased in the last month of search.

For each individual-month-option, we specify the utility to be:

$$
u_{i j t}=\alpha_{0 j} D_{t}+\alpha_{1 j} D_{t} \times \text { Dispute }_{Y}+\gamma A d_{j t}+\alpha_{j t Y}+\varepsilon_{i j t}
$$

where $D_{t}$ is an indicator for the dispute months (Jan-May) in any year, Dispute is $_{Y}$ the treatment year 2011. $A d_{j t}$ is the total advertising spend in that month. $\alpha_{1 j}$ is the treatment effect. $\alpha_{j t Y}$ are year fixed effects. We consider five possible options: 1) the outside option or the no purchase option, 2) purchase on the treated aggregators Orbitz and Expedia, 3) purchase on any of the other aggregators, 4) purchase on the treated airline American, and 5)

purchase on any other airline. The results are robust to treating each domain as a separate option. We construct the advertising variable, $A d_{j t}$, as the sum of Ad spend of all firms within each option.

Assuming the unobserved (to the researcher) shocks follow a Type-1 extreme-value distribution, the probability that individual $i$ books at website $j$ in month $t$ is given by

$$
\operatorname{Pr}_{i j t}(\alpha)=\frac{e^{u_{i j t}(\alpha)}}{\sum_{k \in C} e^{u_{i k t}(\alpha)}}
$$

The overall log-likelihood across all individuals can then be written as

$$
L L(\alpha)=\sum_{i=1}^{N} \sum_{t=1}^{T} \sum_{j=1}^{C} \log \operatorname{Pr}_{i j t}^{\mathrm{I}_{i j t}}(\alpha)
$$


where $\mathrm{I}_{i j t}$ is 1 if individual $i$ booked option $j$ in month $t$, and $C$ is the choice set available to the individual, which includes all airlines and all aggregators.

Table 17 and Figure 5 show the results of the demand estimation. The results indicate during the dispute Orbitz and Expedia see a significant decline in purchases. While there is a decline at other aggregators, American, and other airlines, this decline is neither statistically nor economically significant ${ }^{8}$. Most of the decline goes to the outside option ${ }^{9}$ (which could be consumers using offline travel agents, using other means of transportation, purchasing through an aggregator/airline not included in the analysis, or not participating in the market at all).

To the extent that the tickets booked on Orbitz and Expedia might have been American tickets, this is also potential evidence that American Airlines might also have been impacted negatively. Therefore, to verify whether total demand for American Airlines changes, we use the DB1B database, which tracks passengers (demand) by origin-carrier-quarter.

\footnotetext{
${ }^{8}$ Although the coefficient $\alpha_{1 j}$ is statistically significant for American, when translated to market shares, the change in American's market share is not signficant.

${ }^{9}$ We verify the increase in the "no purchase" option with a simple descriptive regression indicating the result is not from a functional form specification.
} 
Table 17: Demand Estimates using comScore Data

\begin{tabular}{|c|c|c|c|c|c|}
\hline \multirow{2}{*}{ Base: No Purchase } & & \multicolumn{2}{|c|}{$\begin{array}{l}\text { All months } \\
\text { (1) }\end{array}$} & \multicolumn{2}{|c|}{$\begin{array}{l}\text { Last month } \\
\text { (2) }\end{array}$} \\
\hline & & & & & \\
\hline Orbitz + Expedia & & coeff & t-stat & coeff & t-stat \\
\hline Jan-May & $\alpha_{0 j}$ & 0.303 & 7.28 & 1.053 & 24.61 \\
\hline Jan-May X Dispute & $\alpha_{1 j}$ & -0.314 & -4.10 & -0.387 & -4.94 \\
\hline Year $=2011$ & $\alpha_{j, 2011}$ & 0.013 & 0.23 & 0.058 & 1.03 \\
\hline Year $=2010$ & $\alpha_{j, 2}$ & 0.108 & 2.58 & 0.138 & 3.21 \\
\hline Cons & $\alpha_{j}$ & -6.055 & -161.91 & -3.603 & -94.63 \\
\hline \multicolumn{6}{|l|}{ Other Aggregators } \\
\hline Jan-May & $\alpha_{0 j}$ & 0.125 & 2.69 & 0.882 & 18.56 \\
\hline Jan-May X Dispute & $\alpha_{1 j}$ & -0.042 & -0.53 & -0.104 & -1.28 \\
\hline Year $=2011$ & $\alpha_{j, 20}$ & 0.208 & 3.51 & 0.267 & 4.44 \\
\hline Year $=2010$ & $\alpha_{j, 2010}$ & 0.336 & 7.12 & 0.388 & 8.08 \\
\hline Constant & $\alpha_{j}$ & -6.306 & -147.21 & -3.871 & -88.65 \\
\hline
\end{tabular}

American

\begin{tabular}{llrrrr} 
Jan-May & $\alpha_{0 j}$ & 0.175 & 2.68 & 0.921 & 14.00 \\
Jan-May X Dispute & $\boldsymbol{\alpha}_{\mathbf{1 j}}$ & $\mathbf{- 0 . 2 1 9}$ & $\mathbf{- 1 . 9 2}$ & $\mathbf{- 0 . 2 7 6}$ & $\mathbf{- 2 . 4 0}$ \\
Year $=2011$ & $\alpha_{j, 2011}$ & -0.073 & -0.91 & -0.041 & -0.51 \\
Year $=2010$ & $\alpha_{j, 2010}$ & -0.225 & -3.46 & -0.197 & -3.00 \\
Constant & $\alpha_{j}$ & -6.710 & -122.52 & -4.249 & -77.01 \\
\hline
\end{tabular}

\section{Other Airlines}

\begin{tabular}{|c|c|c|c|c|c|}
\hline Jan-May & $\alpha_{0 j}$ & 0.089 & 4.06 & 0.835 & 34.77 \\
\hline Jan-May X Dispute & $\alpha_{1 j}$ & -0.016 & -0.39 & -0.063 & -1.48 \\
\hline Year $=2011$ & $\alpha_{j, 2011}$ & -0.303 & -11.18 & -0.263 & -9.19 \\
\hline Year $=2010$ & $\alpha_{j, 2010}$ & -0.315 & -14.63 & -0.281 & -12.07 \\
\hline Constant & $\alpha_{j}$ & -4.417 & -155.89 & -1.948 & -63.82 \\
\hline Ad & $\gamma$ & $2.00 \mathrm{E}-04$ & 0.18 & $1.00 \mathrm{E}-04$ & 0.06 \\
\hline $\mathrm{N}$ obs & & $1,267,152$ & & 102,050 & \\
\hline $\mathrm{N}$ & & 82,886 & & 82,866 & \\
\hline
\end{tabular}

Note: (1) presents results of a multinomial logit where the outside option of no purchase is constructed using all months all months of search as potential months when a consumer could have purchased a ticket, (2) presents the results assuming the last month of a search is when a purchase would have occurred. Each observation is a purchase at Orbitz or Expedia, at any other aggregators, at American, at any other airline, or a no purchase. 


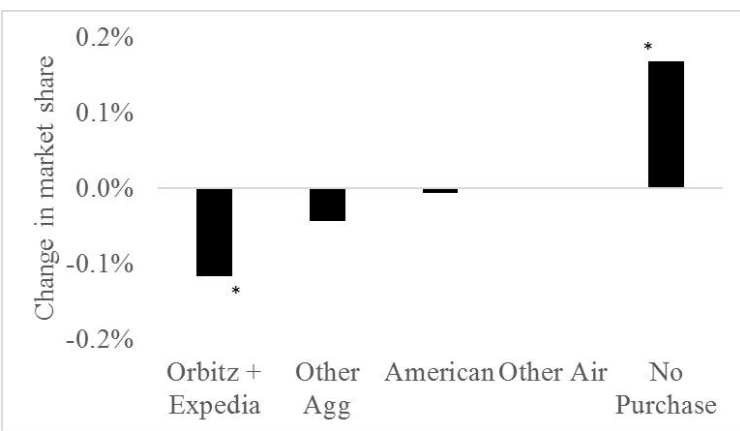

(1)

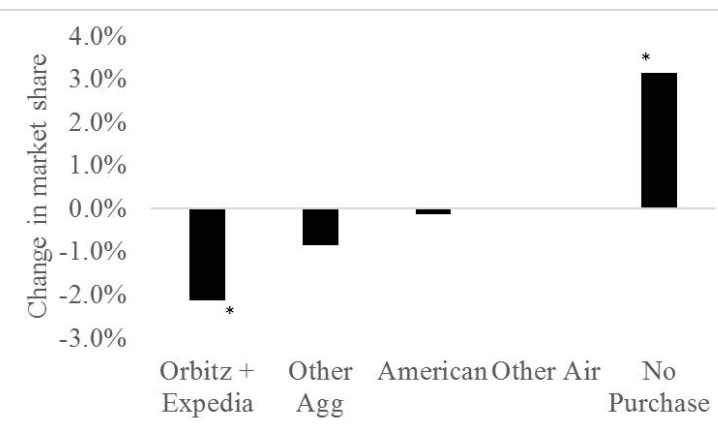

$(2)$

(1): No purchase constructed using all months of search as potential months when a consumer could have purchased a ticket

(2): No purchase constructed using last month of search.

Figure 5: Change in market-share during dispute: Orbitz+Expedia see decline in purchases

\subsubsection{Purchases: DB1B data}

The DB1B data track the number of passengers who fly per quarter through each carrier for every origin-destination pair combination. We use this data to measure changes in American's total demand during the dispute period. This exercise is similar in spirit to Bilotkach et al (2017), who find that demand for American did not change during the dispute period. Similar to their approach, we drop (1) observations with fares that are less than $\$ 0.02$ per mile that are flagged as questionable, (2) markets, i.e., Origin-Destination pairs, with less than 100 passengers in a quarter, (3) itineraries that are not round-trips, and (4) itineraries that have more than 1-stop, i.e., we keep only non-stop and 1-stop itineraries. Itineraries that have the same origin-destination but go through varying stops/layovers are treated equally for purposes of the estimation. For example, we do not distinguish between LAS:CLT:ABE and LAS:PHL:ABE, itineraries with 1 layover originating at Las Vegas (LAS) and ending at Lehigh Valley (ABE). The difference between our approach and Bilotkach et al.'s (2017) is that we include data from and control for the non-dispute quarters as well: this approach allows us to account for any yearly changes in demand that might not have anything to do with the dispute period. We also include the future year (2012) as an additional control and include the top nine airlines (to be consistent with the comScore demand estimation). Finally, we also consider the outside option. We use each zipcode's population to create the market share of the outside option.

We model demand for airline $j$ in a given market (O-D pair) $m$ in quarter $t$, relative to the outside option as: 


$$
\begin{aligned}
\ln \left(s_{j m t}\right)-\ln \left(s_{0 m t}\right) & =\alpha_{0} \operatorname{Disp}_{t}+\alpha_{0} \text { Disp }_{t} \times T_{Y} \\
& +\alpha_{0}^{F} \operatorname{Disp}_{t} \times \text { Focal }_{j}+\alpha_{1}^{F} \text { Disp }_{t} \times T_{Y} \times \text { Focal }_{j} \\
& +\gamma X_{j t}+\alpha_{t Y}+\alpha_{j}+\alpha_{j, t Y}+\alpha_{m}+\varepsilon_{i j t}
\end{aligned}
$$

Here, $s_{m j k t}$ is the share of passengers that flew airline $j$ in origin-destination $(\mathrm{O}-\mathrm{D})$ pair $m$ with number of stops $k$ in quarter $t$, relative to all passengers flying that given O-D pair with the same number of stops and in the quarter. Disp $p_{t}$ is an indicator for the dispute months (Jan-May) in any year, $T_{Y}$ is the treatment year 2011, Focal $_{j}$ is the treated firm American. $X_{j t}$ is the vector of other independent variables such as price, Ads, distance, number of stops. $\alpha_{1}^{F}$ is the treatment effect. $\alpha_{t Y}, \alpha_{j}$ and $\alpha_{j, t Y}$ are year, carrier and year-carrier fixed effects respectively. $\alpha_{m}$ is the $\mathrm{O}-\mathrm{D}$ fixed effect. We instrument for price using jet fuel costs (at the carrier-year-quarter level), number of stops in the itinerary, and the distance between Origin and Destination.

The results of this estimation are reported in Table 18. We find that $\alpha_{1}^{F}$ is not statistically significant from zero, suggesting demand for American Airlines did not change during the dispute period. Table 19 presents the first-stage estimates for price.

In Section 4.4, we account for possible heterogeneity in responses across markets.

Table 18: Demand Estimates using DB1B data

\begin{tabular}{llrr}
\hline & & coeff & t-stat \\
\hline Dispute & $\alpha_{0}$ & -0.281 & -3.09 \\
Dispute X Treatment & $\alpha_{1}$ & 0.000 & 0.00 \\
Dispute X AA & $\alpha_{0}^{F}$ & 0.050 & 0.50 \\
Dispute X Treatment X AA & $\boldsymbol{\alpha}_{\mathbf{1}}^{\boldsymbol{F}}$ & $\mathbf{- 0 . 0 9 2}$ & $\mathbf{- 1 . 5 8}$ \\
& & & \\
price & $\gamma_{P}$ & -0.033 & -3.55 \\
Ads & $\gamma_{A d}$ & $2.2 \mathrm{E}-07$ & 1.28 \\
\hline \multirow{2}{*}{ N obs } & & \\
N O-D & 561,689 & \\
\hline Fixed effects & 12,337 \\
& O-D & \\
& Year \\
& Carrier \\
\hline Cluster & Carrier-Year \\
& O-D \\
\hline price IV & Carrier \\
& fuel cost \\
& stops \\
\hline
\end{tabular}


Table 19: First-stage estimates: Price instrumented using jet fuel costs, number of stops, and $\mathrm{O}-\mathrm{D}$ distance

\begin{tabular}{|c|c|c|}
\hline & coeff & t-stat \\
\hline cost of fuel & 6.880 & 1.50 \\
\hline number of stops & 6.193 & 5.80 \\
\hline mean market distance & 0.037 & 5.33 \\
\hline Dispute & -4.253 & -2.95 \\
\hline Dispute X Treatment & 1.321 & 0.64 \\
\hline Dispute X AA & 0.084 & 0.07 \\
\hline Dispute X Treatment X AA & -2.440 & -2.27 \\
\hline $\mathrm{N}$ obs & 561,689 & \\
\hline $\mathrm{N} \mathrm{O}-\mathrm{D}$ & 12,337 & \\
\hline \multirow[t]{4}{*}{ Fixed effects } & O-D & \\
\hline & Year & \\
\hline & Carrier & \\
\hline & Carrier-Year & \\
\hline \multirow[t]{2}{*}{ Cluster } & $\mathrm{O}-\mathrm{D}$ & \\
\hline & Carrier & \\
\hline
\end{tabular}

\subsection{Heterogeneity in Purchase Behavior}

In this section, similar to the analysis in Section 4.2, where we explore heterogeneity in search intensity motivated by theoretical predictions, we investigate the impact of heterogeneity in the comScore as well as the DB1B database.

\section{comScore data}

We explore the same elements of heterogeneity as for the site visits: 1) American presence, 2) degree of competition and 3) loyalty. Across all groups, there is insufficient power to detect differences in American's sales. Note that in the homogeneous purchase analysis (Figure 5), American experiences a statistically and economically insignificant drop in market share. For the treated aggregators, we find evidence for a heterogeneous response by loyalty: those most loyal to the aggregators see no change in their transactions, while those who are least loyal see the biggest drop in transactions. We conduct the same analysis as in Section 4.3.1 but split by each loyalty group. Figure 6 plots the resulting estimated market share changes for the treated aggregators by the various loyalty groups.

We do not find a significant difference in purchases between the low vs high competition airports. We do find a statistically significant difference between areas where American is neither absent nor most important relative to areas where there is no American present. 
However, this difference is not statistically different from areas with high American presence relative to areas where there is no American present.
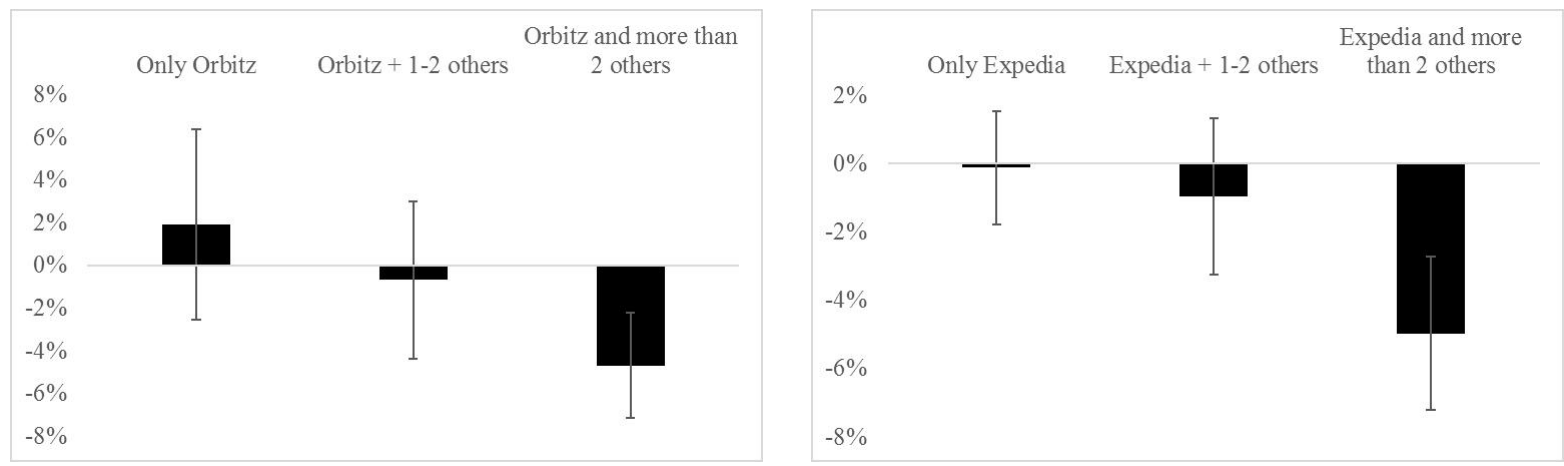

Note: No purchase option constructed using last month of search.

Figure 6: Drop in treated aggregators' share by loyalty: those least loyal drop their purchases on Orbitz and Expedia

\section{DB1B data}

We find a decline in American's market share in areas 1) where American is not a prominent airline $^{10}$ and 2) with low airline competition. Tables 20 and 21 present the results of these two heterogeneity analyses. This finding aligns with our findings in the search heterogeneity analysis where the treated aggregators are negatively impacted in these areas (Tables 10 and 11), suggesting the decline in visits and purchases at the treated aggregators translates to a decline in American's passenger load in certain regions.

A back-of-the-envelope calculation, using the mean market shares of the outside option in the non-dispute period, and the estimated decrease from Table 20 during the dispute period (-0.158) implies a $15 \%$ decline in passenger load in areas where American is not a prominent airline. Using the passenger count in these airports in 2010 (the control period), where the total number of passengers is 273,000, this drop translates to 41,000 lost passengers. Compared to American's annual passenger count in these areas, this is a $1.4 \%$ drop.

\footnotetext{
${ }^{10}$ For airports with no American presence, by definition, market share of American is zero in such airports, and estimation is not feasible. While the comScore data has sufficient observations for people living near such airports and browsing aa.com,orbitz.com and expedia.com, these airports (by construction) have no market share in the DB1B database.
} 
Table 20: Purchases at American, by varying degrees of American presence

\begin{tabular}{|c|c|c|}
\hline American is most important & $\begin{array}{r}\text { airline in ail } \\
\text { coeff }\end{array}$ & $\begin{array}{c}\text { cport } \\
\text { t-stat }\end{array}$ \\
\hline Dispute & -0.246 & -3.53 \\
\hline Dispute X Treatment & 0.059 & 1.58 \\
\hline Dispute X AA & 0.105 & 1.36 \\
\hline Dispute X Treatment X AA & -0.029 & -0.77 \\
\hline price & -0.021 & -3.46 \\
\hline Ads & $\gamma_{A d} \quad 1.61 \mathrm{E}-07$ & 1.55 \\
\hline $\mathrm{N}$ obs & 140,873 & \\
\hline $\mathrm{N} \mathrm{O}-\mathrm{D}$ & 3,161 & \\
\hline American neither absent nor & $\begin{array}{r}\text { most impor } \\
\text { coeff }\end{array}$ & $\begin{array}{c}\text { tant } \\
\text { t-stat }\end{array}$ \\
\hline Dispute & -0.281 & -2.82 \\
\hline Dispute X Treatment & -0.029 & -0.40 \\
\hline Dispute X AA & -0.006 & -0.05 \\
\hline Dispute $\mathrm{X}$ Treatment $\mathrm{X}$ AA & -0.158 & -2.06 \\
\hline price & -0.036 & -3.23 \\
\hline Ads & $\gamma_{A d} 2.41 \mathrm{E}-07$ & 1.16 \\
\hline $\mathrm{N}$ obs & 420,816 & \\
\hline $\mathrm{N} \mathrm{O}-\mathrm{D}$ & 9,176 & \\
\hline Fixed effects & O-D & \\
\hline & Year & \\
\hline & Carrier & \\
\hline & Carrier-Year & \\
\hline Cluster & $\mathrm{O}-\mathrm{D}$ & \\
\hline & Carrier & \\
\hline price IV & $\begin{array}{l}\text { fuel cost } \\
\text { stops } \\
\text { distance }\end{array}$ & \\
\hline
\end{tabular}


Table 21: Purchases at American, by varying degrees of competition

(1) High competition airports

\begin{tabular}{lcrr} 
& & coeff & t-stat \\
\hline Dispute & $\beta_{0}$ & -0.397 & -5.64 \\
Dispute X Treatment & $\beta_{1}$ & 0.136 & 3.18 \\
Dispute X AA & $\beta_{0}^{F}$ & 0.100 & 2.02 \\
Dispute X Treatment X AA $\boldsymbol{\beta}_{\mathbf{1}}^{\boldsymbol{F}}$ & $\mathbf{0 . 1 2 4}$ & $\mathbf{1 . 3 2}$
\end{tabular}

\begin{tabular}{lrrr} 
price & $\gamma_{P}$ & -0.027 & -3.79 \\
Ads & $\gamma_{A d}$ & $1.04 \mathrm{E}-07$ & 0.41 \\
\hline
\end{tabular}

$\mathrm{N}$ obs $\quad 30,900$

$\mathrm{N} \mathrm{O-D} 549$

(2) Low competition airports

\begin{tabular}{llrr} 
& & coeff & t-stat \\
\hline Dispute & $\beta_{0}$ & -0.296 & -3.14 \\
Dispute X Treatment & $\beta_{1}$ & 0.008 & 0.18 \\
Dispute X AA & $\beta_{0}^{F}$ & 0.021 & 0.19 \\
Dispute X Treatment X AA $\boldsymbol{\beta}_{\mathbf{1}}^{\boldsymbol{F}}$ & $\mathbf{- 0 . 2 9 3}$ & $\mathbf{- 2 . 5 5}$
\end{tabular}

\begin{tabular}{llrr} 
price & $\gamma_{P}$ & -0.042 & -3.41 \\
Ads & $\gamma_{A d}$ & $1.24 \mathrm{E}-07$ & 0.47 \\
\hline
\end{tabular}

\begin{tabular}{ll} 
N obs & 132,402 \\
N O-D & 2,735 \\
\hline
\end{tabular}

Fixed effects O-D

\begin{tabular}{ll} 
& Year \\
& Carrier \\
& Carrier-Year \\
\hline Cluster & O-D \\
& Carrier \\
\hline price IV & fuel cost \\
& stops \\
& distance \\
\hline
\end{tabular}

\subsection{Economic significance}

The average site visits on Orbitz, across all users who visit travel-related websites, is 0.38. Compared to this value, a drop in monthly site visits of 0.041 (Table 5) amounts to an $11 \%$ decline. To put this decline in perspective, as of year-end 2010, Orbitz's yearly revenue from advertising and media revenue was $\$ 49.4 \mathrm{~m}$, accounting for $6.5 \%$ of its total revenue 
(Orbitz 10K, 2010). For Orbitz, advertising and media revenue largely consists of revenue from display ads, which is directly proportional to the number of site visits. With an $11 \%$ decline in site visits, the drop in Orbitz's revenue is $\$ 5.32 \mathrm{~m}$. Similarly, Expedia would face a revenue loss of $\$ 9.13 \mathrm{~m}$.

Orbitz's standalone air revenue was $\$ 274.6$ year-end 2010, and $\$ 265 \mathrm{~m}$ year-end 2011, implying a $3 \%$ decline in air revenue from 2010 to 2011. This amount is close to our estimated $2.16 \%$ decline in market-share reported in section 4.3.1, Figure 5. These numbers show that Orbitz lost a significant source of its revenue stream during the dispute period.

\subsection{Discussion}

The event study design assumes the only change that occurred during the treatment period is the American-Orbitz dispute. To the extent other events might have occurred in the travel industry we are measuring the net effect of these events. Two events that might be of concern are the United-Continental merger that was announced in May 2010 and transpired in November 2011, and the American's bankruptcy filing in November 2011. However, the following findings give us greater confidence that we are indeed measuring the impact of the dispute. First, while we might expect American Airlines to be impacted by these events, Orbitz and Expedia should not be disproportionately (compared to other aggregators) impacted by these events. The fact that these two aggregators are the ones that see a drop in visits give us greater confidence that we are indeed measuring the impact of the dispute. This drop in visits for these two aggregators hold under a host of robustness checks. Second, in our loyalty analysis we find that the group of users who are most loyal to American airlines and use aggregators to augment their search, are the ones who increase their site visitation on American. Users who are not loyal to American (i.e., visit multiple other airlines) do not exhibit this increase, nor do users who are completely loyal to American but do not augment their search with aggregators. Moreover, Delta users do not exhibit such a pattern. If American is benefited because of the United Continental merger, then we should not see a disproportionate increase in American's visits by American loyalists who use aggregators, and no increase by American loyalists who do not visit any other site. It is also unclear why American, and not Delta, should be likely to benefit from this merger. The dispute explains these patterns better.

Finally, it is possible that in response to the dispute, the impacted domains as well as their competitors, could have altered their marketing variables. We therefore verify airlines' prices and all travel websites' advertising responses in the following section. If firms made changes to other marketing variables for which we do not have data, such changes would not 
be captured.

\section{$5 \quad$ Firm Response}

\subsection{Prices}

We first check for airlines' price responses, where prices are observed using the DB1B database. This exercise is similar in spirit to Bilotkach et al (2017), who find that American's fares dropped during the dispute period. We subset the DB1B using the same criteria described in Section 4.3.2. We calculate the average fare at the airline-year-quarter-origindestination-number of stops level. The difference between our approach and Bilotkach et al.'s (2014) is that we include data from and control for the non-dispute quarters as well: this approach allows us to control for any yearly changes in prices that might not have anything to do with the dispute period; for example, if American dropped its prices in 2011, merely including 2011 Q1 data might mislead us to infer the drop was due to the dispute. We also include the future year (2012) as an additional control and include the top nine airlines (to be consistent with the demand estimation). Finally, we also control for jet fuel costs which vary by airline and month, available from the Bureau of Transportation Statistics ${ }^{11}$.

The basic price regression we estimate is:

$$
\begin{aligned}
\ln \left(p_{m j k t}\right) & =\delta_{0} D_{t}+\delta_{1} D_{t} \times \text { Disp }_{Y} \\
& +\delta_{0}^{F} D_{t} \times \text { Focal }_{j}+\delta_{1}^{F} D_{t} \times \text { Disp }_{Y} \times \text { Focal }_{j} \\
& +\alpha_{t Y}+\alpha_{t Y}^{F} \text { Focal }_{j}+\alpha_{j}+\alpha_{m} \\
& +\delta_{3} \text { cost }_{j t}+\varepsilon_{m j k t}
\end{aligned}
$$

where $m$ is an Origin-Destination pair, $j$ is the airline, $k$ is the number of stops, and $t$ is the quarter. Here, $p_{m j k t}$ is the passenger-weighted average airfare charged by airline $j$ in market $m$ with number of stops $k$ in quarter $t$. We add additional controls, such as the number of stops and distance between the origin and destination.

Table 22 reports results of this regression using various controls. $\delta_{1}^{F}$ gives us the change in American's prices relative to competitors and the baseline years. Specification (1) reports the estimates from the basic regression in equation 6 , which controls for origin-destination, year, and carrier fixed effects. Specification (2) adds controls for carrier-year fixed effects as well, (3) adds the distance between the origin-destination pair as an additional control, (4) adds market share, and (5) adds a control for the number of stops. As can be seen,

\footnotetext{
${ }^{11}$ https://www.transtats.bts.gov/fuel.asp
} 
American fares in 2011 seem to decrease relative to 2010 and 2012. However, this decrease is not statistically significant. This pattern is true across all specifications (1)-(5). Moreover, this result is robust to using the unweighted average fare as well.

While these results are directionally consistent with Bilotkach et al.'s (2017) findings, unlike their finding we find little evidence of a statistically significant drop. One possible reason for this difference is our inclusion of jet fuel costs as an explanatory variable. Figure 7 plots the difference in jet fuel prices between American and all major carriers. We see that American faced lower fuel costs during the dispute period. Therefore, not including this cost control attributes all the change in prices to the dispute. American's 10k report, which states that due to the company's fuel hedging program they saw a decrease in fuel expenses in 2011 (American 10K, 2011), is consistent with figure 7.

Table 22: Prices during the dispute and control periods: Estimates using DB1B data

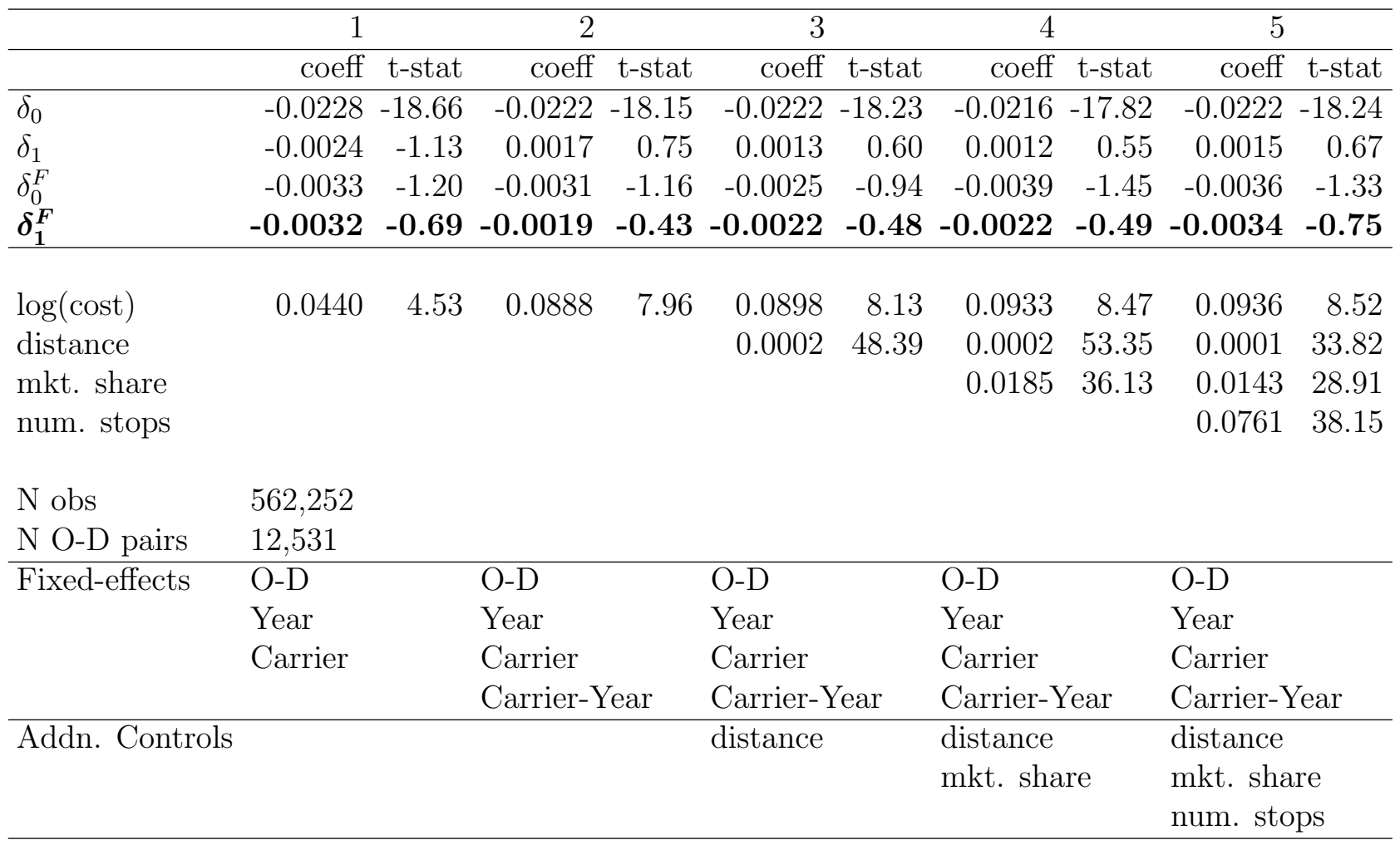

Note: Table presents diff-in-diff regression results for $\log$ (weighted market fare) with a number of different controls. DB1B quarterly data at the market $(\mathrm{O}-\mathrm{D})$, carrier level used. 


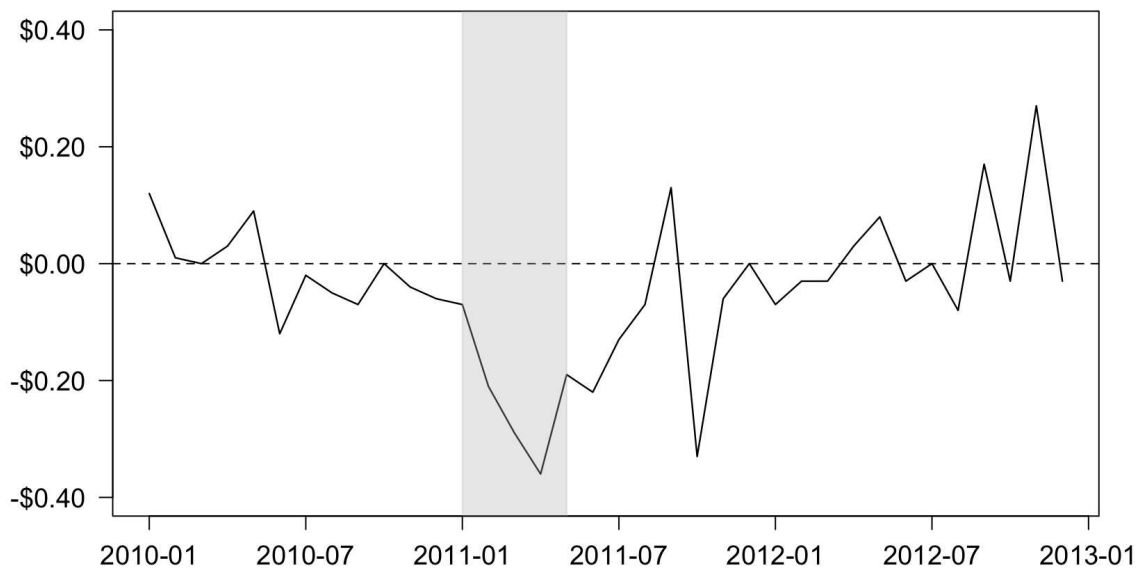

Note: The grey shaded area represents the dispute months, January-May 2011.

Source: Bureau of Transportation Statistics.

Figure 7: Difference between American's and All Major Carriers' Cost per gallon of airline fuel (dollars)

\subsection{Advertising}

We use the Nielsen Monitor-Plus Media data, which consists of National TV, Spot TV, Internet, Magazines, Newspapers, Outdoors and Radio ad spend along with the airing date and the advertised brand. We focus on ad spend as the relevant metric and verify if any of the impacted domains changed their ad spend in the dispute period using the regression specification

$$
\begin{aligned}
\ln \left(A d_{j t}\right) & =\gamma_{0} D_{t}+\gamma_{1} D_{t} \times \text { Disp }_{Y} \\
& +\gamma_{0}^{F} D_{t} \times \text { Focal }_{j}+\gamma_{1}^{F} D_{t} \times \text { Disp }_{Y} \times \text { Focal }_{j} \\
& +\alpha_{t Y}+\alpha_{t Y}^{F} \text { Focal }_{j}+\varepsilon_{i j t}
\end{aligned}
$$

where $A d_{j t}$ is the advertising spend of brand $j$ in month $t . D_{t}=1$ if $t$ is between January and May, the months relevant to the dispute period, $\operatorname{Disp}_{Y}=1$ if the months correspond to the year the dispute occurred (2011). Focal ${ }_{j}$ is an indicator that equals 1 if travel domain $j$ is the impacted domain, i.e., American, Orbitz, or Expedia. We test is $\gamma_{1}^{F}=0$ which would imply ad spend in the control and dispute periods are similar. Table 23 reports the relevant estimate, $\gamma_{1}^{F}$, for each of the advertising media types for which we have data. 
Table 23: Change in log of Ad Spend, relative to competitors and control period

\begin{tabular}{lrrrrrrr}
\hline & \multicolumn{2}{c}{ aa.com } & \multicolumn{2}{c}{ orbitz.com } & \multicolumn{2}{c}{ expedia.com } & $\mathrm{N}$ obs \\
\hline & coeff & t-stat & coeff & t-stat & coeff & t-stat & \\
\hline Internet & -1.690 & -1.93 & -1.496 & -2.41 & -2.651 & -4.43 & 991 \\
Magazines & -3.654 & -2.78 & -0.352 & -0.34 & -4.686 & -4.34 & 769 \\
Network TV & -3.915 & -5.56 & -0.885 & -1.04 & -0.723 & -0.80 & 514 \\
Spot TV & -1.773 & -2.16 & 0.290 & 0.39 & -0.851 & -1.09 & 815 \\
Newspapers & 0.002 & 0.00 & N/A & N/A & 0.990 & 1.51 & 707 \\
Outdoors & -1.543 & -1.40 & N/A & N/A & N/A & N/A & 480 \\
Radio & -1.143 & -2.05 & N/A & N/A & -1.479 & -3.57 & 688 \\
& & & & & & \\
\hline Cluster & Brand \\
Observation & Brand x Sub-brand x year x month \\
\hline
\end{tabular}

Overall, there appears to be a decline in ad spend by American. Both Orbitz and Expedia appear to have decreased their ad spend pertaining to display ads. There are insufficient observations in Newspaper, Outdoor and Radio to make meaningful conclusions. To better understand the decrease in display ad spend by the impacted domains, we look at each domain separately. Interestingly, we find that this relative decrease in ad spend is driven by other aggregators (Cheapflights, Priceline) and airlines (Alaska, JetBlue) increasing their ad spend during the dispute period. This could be a competitive response by players such as Priceline and Cheapflights to make the most of Orbitz's shortcomings during the dispute period. Both Orbitz and Travelocity increased their magazine spending, partly influencing the relative decline in American's and Expedia's magazine ad spend. All these changes in advertising spending, which could be strategic responses by firms and their competitors, further highlights the need to control for this marketing variable in our demand analysis (Equations 4 and 5).

\section{Conclusion}

In the context of the airline industry, we find that airlines have more market power than the aggregator. The aggregator stands to lose, in terms of consumers visiting its website and purchases, when it is not comprehensive. The consumer heterogeneity patterns in the data further support this conclusion. Consumers who live near airports where a non-American airline is prominent (e.g., United) drop their usage of Orbitz the most. It is for these consumers that American's flight and fare information is perhaps the most useful: they likely already know United's flights and fares and would want to know if there are other better 
offerings. Not finding information about a relevant competitor makes Orbitz a less useful site. For an aggregator where a sizable portion of the revenue comes from ad placements, this implies an economically significant drop in revenue.

Our finding accentuates the necessity of understanding market power on a case by case basis and is relevant to policy makers and regulatory authorities. In our setting, we find the biggest decline in usage of Orbitz and Expedia is among users who view aggregators as close substitutes, indicating our results might apply to settings where there are multiple aggregators and users can easily substitute between them. The findings might look very different in a category where there is only one dominant aggregator (e.g. Amazon in the online retail setting) or where there are numerous firms (e.g. the hotel industry). Even in such cases individual firms might have different degrees of market power. We hope future research will analyze more cases to understand the market power relationship in different contexts.

This paper examines a short-run effect, constrained by the dispute which lasted five months. Long-run effects might be very different and might lead to higher equilibrium prices. It might also lead to changes in airlines' marketing strategy if they choose to no longer be part of an aggregator, as airlines have to work harder to increase their probability of discovery.

\section{References}

[1] Ailawadi, K. L., E.T. Bradlow, M. Draganska, , V. Nijs, R.P. Rooderkerk, K. Sudhir, K.C. Wilbur and J. Zhang (2010), "Empirical models of manufacturer-retailer interaction: a review and agenda for future research", Marketing Letters, 21(3), 273-285.

[2] American 10K (2010), "AMR Corporation Form 10-K", https://americanairlines.gcsweb.com/sec-filings/sec-filing/10-k/0001193125-12-063516

[3] Athey, S., M. Mobius and J. Pal (2017), "The Impact of Aggregators on Internet News Consumption", Stanford GSB working paper.

[4] Baye, M.R. and J. Morgan (2001), "Information Gatekeepers on the Internet and the Competitiveness of Homogeneous Product Markets", The American Economic Review, $91(3), 454-474$

[5] Bilotkach, V., N.Rupp and V. Pai (2017), "Value of a Platform to a Seller: Case of American Airlines and Online Travel Agencies," working paper. 
[6] Calzada, J. and R. Gil (2016), "What do News Aggregators Do? Evidence from Google News in Spain and Germany", SSRN working paper.

[7] Chiou L. and C. Tucker (2017), "Content aggregation by platforms: The case of the news media", Journal of Economics and Management Strategy, 00:1-24.

[8] Draganska, M., D. Klapper, \& S. Villas-Boas (2010), "A larger slice or a larger pie: an empirical investigation of bargaining power in the distribution channel", Marketing Science, 29, 57-74.

[9] eBizMBA (2020), "Top 15 Most Popular Travel Websites", http://www.ebizmba.com/articles/travel-websites

[10] Lambert, D. (1992), "Zero-Inflated-Poisson-Regression-With-An-Application-toDefects-in-Manufacturing", Technometrics, 34(1), 1-14.

[11] Noton, C. and A. Elberg (2018), "Are supermarkets squeezing small suppliers? Evidence from negotiated wholesale prices", The Economic Journal, forthcoming.

[12] O’Brien, D.P. and G. Shaffer (1997), "Nonlinear Supply Contracts, Exclusive Dealing, and Equilibrium Market Foreclosure", Journal of Economics \& Management Strategy, $6(4), 755-785$.

[13] Orbitz 10K (2010), "Orbitz Worldwide, Inc. Form 10-K", http://phx.corporateir.net $/$ mobile.view? $=212312 \& v=200 \& \mathrm{~d}=3 \& \mathrm{id}=7446122$

[14] Reuters (2018), "EU antitrust chief keeps open threat to break up Google", Reuters News, March 252018.

[15] Time (2011), "How Travelers Could Lose in American's Web Ticket War", by Kayla Webley, Jan 062011.

[16] Washington Post (2011), "Travelers Turn Back to Travel Agents", by Nancy Trejos, April 252011.

[17] Villas-Boas, M. J., \& Y. Zhao (2005), "Retailer, manufacturers, and individual consumers: modeling the supply side in the ketchup marketplace", Journal of Marketing Research, 42(1), 83-95. 


\section{A Lonely Planet and Treated Firms: Descriptives}

Table 24: Demographics for users of LonelyPlanet and treated firms

\begin{tabular}{|c|c|c|c|c|}
\hline \multirow{2}{*}{ Household Incom } & LonelyPlanet & Orbitz & Expedia & American \\
\hline & & & & \\
\hline 1 Less than $15 \mathrm{k}$ & $13 \%$ & $13 \%$ & $13 \%$ & $13 \%$ \\
\hline $215 \mathrm{k}-24.999 \mathrm{k}$ & $8 \%$ & $9 \%$ & $9 \%$ & $8 \%$ \\
\hline $325 \mathrm{k}-34.999 \mathrm{k}$ & $10 \%$ & $10 \%$ & $10 \%$ & $9 \%$ \\
\hline $435 \mathrm{k}-49.999 \mathrm{k}$ & $11 \%$ & $12 \%$ & $12 \%$ & $11 \%$ \\
\hline $550 \mathrm{k}-74.999 \mathrm{k}$ & $23 \%$ & $24 \%$ & $24 \%$ & $23 \%$ \\
\hline $675 \mathrm{k}-99.999 \mathrm{k}$ & $15 \%$ & $15 \%$ & $15 \%$ & $16 \%$ \\
\hline $7100 \mathrm{k}+$ & $21 \%$ & $17 \%$ & $18 \%$ & $20 \%$ \\
\hline \multicolumn{5}{|l|}{ Household Size } \\
\hline 11 & $15 \%$ & $18 \%$ & $18 \%$ & $18 \%$ \\
\hline 22 & $26 \%$ & $27 \%$ & $27 \%$ & $28 \%$ \\
\hline 33 & $20 \%$ & $19 \%$ & $19 \%$ & $18 \%$ \\
\hline 44 & $17 \%$ & $15 \%$ & $16 \%$ & $16 \%$ \\
\hline 55 & $14 \%$ & $13 \%$ & $13 \%$ & $13 \%$ \\
\hline $66+$ & $8 \%$ & $7 \%$ & $8 \%$ & $7 \%$ \\
\hline \multicolumn{5}{|l|}{ Racial Background } \\
\hline 1 White & $67 \%$ & $67 \%$ & $67 \%$ & $64 \%$ \\
\hline 2 Black & $9 \%$ & $14 \%$ & $15 \%$ & $14 \%$ \\
\hline 3 Asian & $10 \%$ & $6 \%$ & $6 \%$ & $6 \%$ \\
\hline 5 Other & $13 \%$ & $13 \%$ & $12 \%$ & $16 \%$ \\
\hline \multicolumn{5}{|c|}{ Census Region of Residence } \\
\hline 1 Northeast & $22 \%$ & $21 \%$ & $21 \%$ & $22 \%$ \\
\hline 2 North Central & $19 \%$ & $19 \%$ & $18 \%$ & $17 \%$ \\
\hline 3 South & $33 \%$ & $36 \%$ & $36 \%$ & $41 \%$ \\
\hline 4 West & $25 \%$ & $25 \%$ & $25 \%$ & $20 \%$ \\
\hline \multicolumn{5}{|c|}{ Age of Eldest Head of Household and Age of user } \\
\hline $118-20$ & $3 \%$ & $2 \%$ & $2 \%$ & $2 \%$ \\
\hline $221-24$ & $5 \%$ & $5 \%$ & $5 \%$ & $4 \%$ \\
\hline $325-29$ & $8 \%$ & $9 \%$ & $9 \%$ & $8 \%$ \\
\hline 4 30-34 & $8 \%$ & $9 \%$ & $9 \%$ & $8 \%$ \\
\hline $535-39$ & $8 \%$ & $9 \%$ & $10 \%$ & $10 \%$ \\
\hline 6 40-44 & $12 \%$ & $12 \%$ & $12 \%$ & $12 \%$ \\
\hline $745-49$ & $15 \%$ & $13 \%$ & $13 \%$ & $13 \%$ \\
\hline $850-54$ & $14 \%$ & $13 \%$ & $12 \%$ & $12 \%$ \\
\hline \multicolumn{5}{|l|}{ Connection Speed } \\
\hline 0 Not broadband & $1 \%$ & $1 \%$ & $1 \%$ & $1 \%$ \\
\hline 1 Broadband & $99 \%$ & $99 \%$ & $99 \%$ & $99 \%$ \\
\hline \multicolumn{5}{|l|}{ Country of Origin } \\
\hline 0 Non-Hispanic & $87 \%$ & $88 \%$ & $88 \%$ & $81 \%$ \\
\hline 1 Hispanic & $13 \%$ & $12 \%$ & $12 \%$ & $19 \%$ \\
\hline \multicolumn{5}{|l|}{ Child Present } \\
\hline $0 \mathrm{No}$ & $32 \%$ & $35 \%$ & $34 \%$ & $37 \%$ \\
\hline 1 Yes & $68 \%$ & $65 \%$ & $66 \%$ & $63 \%$ \\
\hline $\mathrm{N}$ ids & 6,738 & 52,848 & 100,401 & 28,098 \\
\hline
\end{tabular}



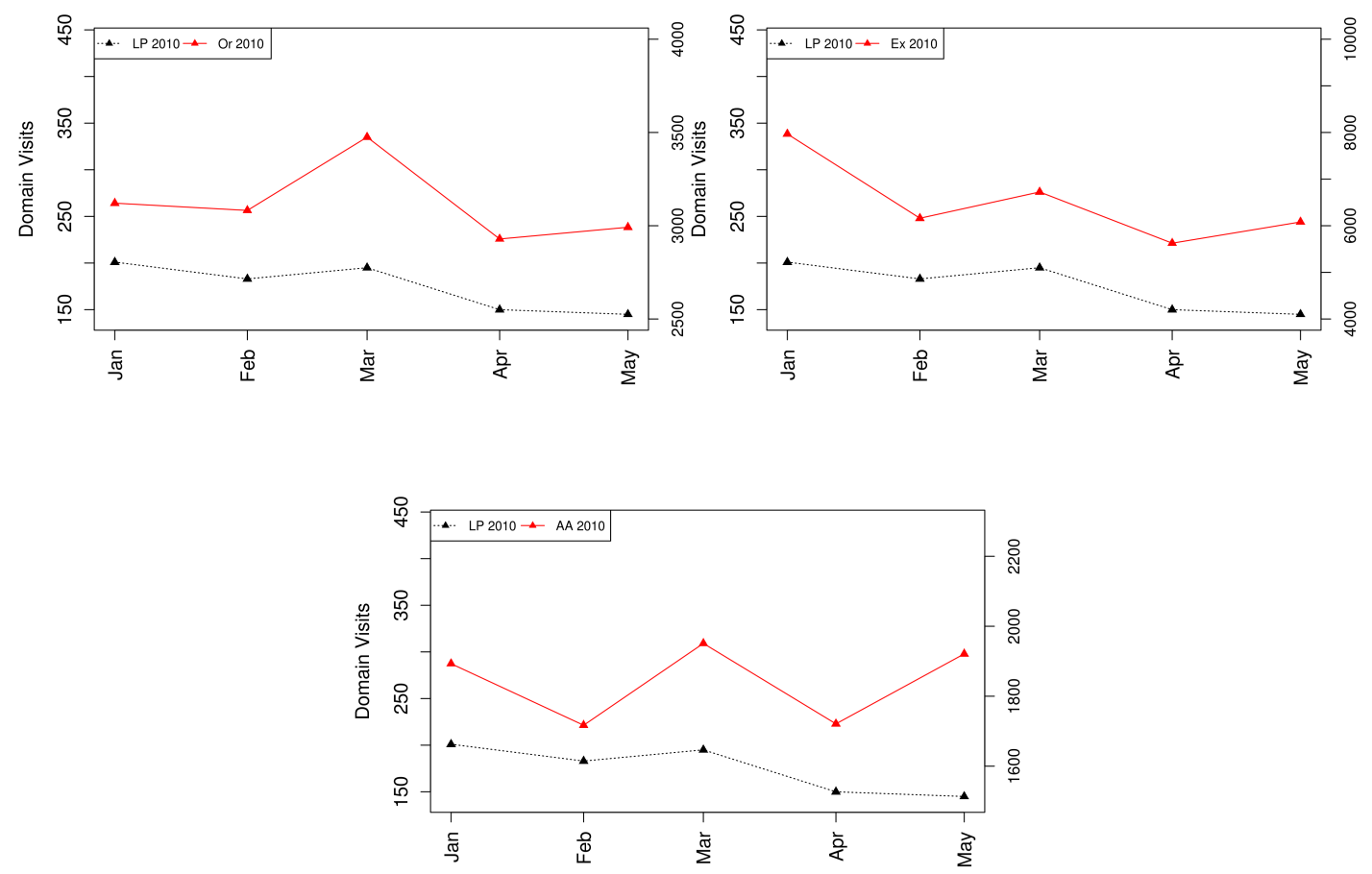

Figure 8: Parallel Trends of LonelyPlanet and treated firms in control period 2010
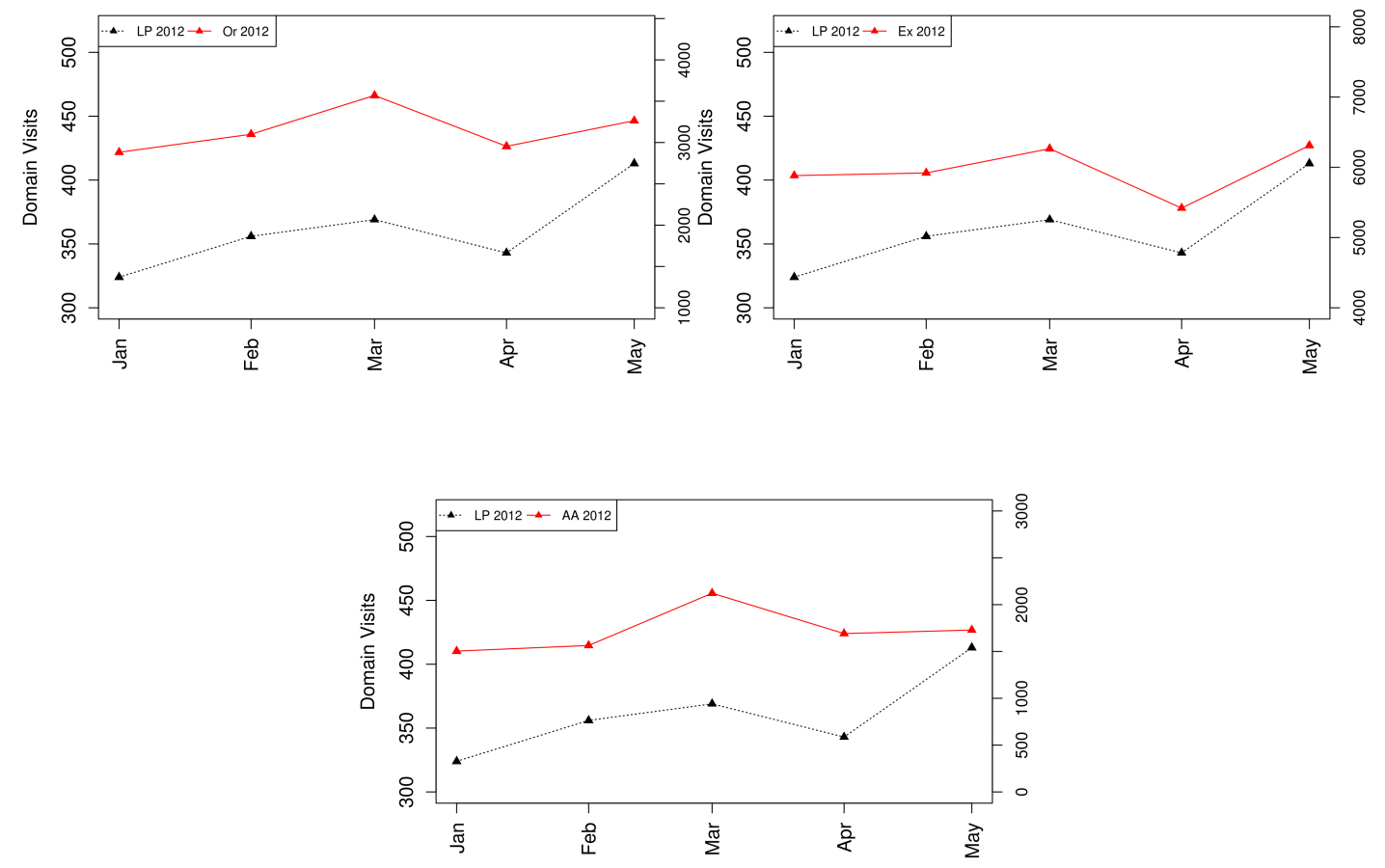

Figure 9: Parallel Trends of LonelyPlanet and treated firms in control period 2012 
Table 25: Correlation between LonelyPlanet and treated firms' site visits during control months

\begin{tabular}{lrr}
\hline & 2010 & 2012 \\
\hline Orbitz & 0.70 & 0.62 \\
Expedia & 0.80 & 0.70 \\
American & 0.27 & 0.40 \\
\hline
\end{tabular}




\section{B Search Estimates: Robustness Checks}

Table 26: Using only last 1 month as relevant to the (intended) purchase

\begin{tabular}{lcrrrrrr}
\hline & \multicolumn{2}{c}{ aa.com } & orbitz.com & \multicolumn{2}{c}{ expedia.com } \\
\hline (1) sites & \multicolumn{1}{c}{ coeff } & t-stat & coeff & t-stat & coeff & t-stat \\
& $\beta_{0}$ & 0.074 & 4.71 & 0.088 & 8.05 & 0.095 & 4.91 \\
Jan-May & $\beta_{1}$ & 0.023 & 1.33 & -0.002 & -0.08 & -0.009 & -0.30 \\
Jan-May X Dispute & $\beta_{0}^{F}$ & -0.001 & -0.10 & 0.051 & 5.08 & 0.043 & 3.28 \\
Jan-May X Focal & $\boldsymbol{\beta}_{\mathbf{1}}$ & $\mathbf{0 . 0 2 1}$ & $\mathbf{1 . 4 9}$ & $\mathbf{- 0 . 0 8 4}$ & $\mathbf{- 4 . 9 0}$ & $\mathbf{- 0 . 0 8 6}$ & $\mathbf{- 3 . 9 6}$ \\
Jan-May X Dispute X Focal & & & & & & \\
Ad spend & $\gamma$ & $-7.27 \mathrm{E}-10$ & -0.39 & $2.05 \mathrm{E}-09$ & 0.80 & $2.43 \mathrm{E}-08$ & 3.75 \\
\hline
\end{tabular}

(2) duration

\begin{tabular}{|c|c|c|c|c|c|c|c|}
\hline & & coeff & t-stat & coeff & t-stat & coeff & t-sta \\
\hline Jan-May & $\beta_{0}$ & 0.845 & 6.28 & 1.359 & 9.32 & 2.035 & 9. \\
\hline Jan-May X Dispute & $\beta_{1}$ & 0.613 & 2.46 & -0.012 & -0.05 & -0.367 & -1 . \\
\hline Jan-May X Focal & $\beta_{0}^{F}$ & 0.397 & 3.05 & 0.927 & 7.61 & 1.394 & 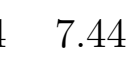 \\
\hline Jan-May X Dispute X Focal & $\beta_{1}^{F}$ & -0.033 & -0.16 & -0.855 & -4.01 & -1.047 & -3 \\
\hline Ad spend & $\gamma$ & $-8.10 \mathrm{E}-09$ & -0.28 & $1.84 \mathrm{E}-08$ & 0.62 & 1.42E-07 & \\
\hline
\end{tabular}

(3) pages

\begin{tabular}{llrrrrrr} 
& & \multicolumn{1}{c}{ coeff } & t-stat & coeff & \multicolumn{1}{c}{ t-stat } & coeff & t-stat \\
\hline Jan-May & $\beta_{0}$ & 1.304 & 6.82 & 1.105 & 8.37 & 1.378 & 9.45 \\
Jan-May X Dispute & $\beta_{1}$ & -0.125 & -0.49 & -0.118 & -0.61 & -0.349 & -1.50 \\
Jan-May X Focal & $\beta_{0}^{F}$ & 0.838 & 4.86 & 0.694 & 6.53 & 1.109 & 7.65 \\
Jan-May X Dispute X Focal & $\boldsymbol{\beta}_{\mathbf{1}}^{\boldsymbol{F}}$ & $\mathbf{- 0 . 6 8 3}$ & $\mathbf{- 3 . 0 6}$ & $\mathbf{- 0 . 5 9 7}$ & $\mathbf{- 3 . 2 8}$ & $\mathbf{- 0 . 9 8 1}$ & $\mathbf{- 4 . 9 3}$ \\
& & & & & & & \\
Ad spend & $\gamma$ & $-1.48 \mathrm{E}-08$ & -0.48 & $3.43 \mathrm{E}-08$ & 1.20 & $2.59 \mathrm{E}-07$ & 4.49 \\
\hline & & & & & & \\
$\mathrm{N}$ obs & 207,756 & & & & & \\
$\mathrm{~N}$ id & 83,991 & & & & \\
Fixed effects & id, year, year X focal & & & & \\
Cluster & id
\end{tabular}

Note: Tables present diff-in-diff analyses, using Lonely Planet as a control, for each of the three dependant variables (1) sites, (2) duration and (3) pages. Only the last month of search is used. Each table presents 3 separate regressions run for each of the impacted domains, aa.com, orbitz.com and expedia.com. JanMay is an indicator for the five months January-May, Dispute is an indicator for the year of the dispute 2011 , Focal is an indicator for the impacted domain $\boldsymbol{\beta}_{\mathbf{1}}^{\boldsymbol{F}}$ is the relevant treatment effect. 
Table 27: Using only last 2 months as relevant to the (intended) purchase

\begin{tabular}{lcrrrrrr}
\hline & & \multicolumn{2}{c}{ aa.com } & \multicolumn{2}{c}{ orbitz.com } & \multicolumn{2}{c}{ expedia.com } \\
\hline (1) sites & & & & & & & \\
& & coeff & t-stat & coeff & t-stat & coeff & t-stat \\
\hline Jan-May & $\beta_{0}$ & 0.032 & 6.72 & 0.051 & 9.96 & 0.066 & 9.10 \\
Jan-May X Dispute & $\beta_{1}$ & -0.002 & -0.22 & -0.005 & -0.55 & -0.010 & -0.79 \\
Jan-May X Focal & $\beta_{0}^{F}$ & -0.026 & -2.97 & 0.019 & 2.06 & 0.022 & 1.99 \\
Jan-May X Dispute X Focal & $\boldsymbol{\beta}_{\mathbf{1}}^{\boldsymbol{F}}$ & $\mathbf{0 . 0 2 4}$ & $\mathbf{1 . 9 2}$ & $\mathbf{- 0 . 0 6 2}$ & $\mathbf{- 3 . 8 6}$ & $\mathbf{- 0 . 0 6 2}$ & $\mathbf{- 3 . 2 5}$ \\
& & & & & & & \\
Ad spend & $\gamma$ & $4.77 E-09$ & 2.82 & $2.32 \mathrm{E}-09$ & 1.03 & $1.23 \mathrm{E}-08$ & 2.61 \\
\hline
\end{tabular}

(2) duration

\begin{tabular}{|c|c|c|c|c|c|c|c|}
\hline & & coeff & t-stat & coeff & t-stat & coeff & t-stat \\
\hline Jan-May & $\beta_{0}$ & 0.340 & 6.22 & 0.471 & 8.99 & 0.752 & 9.15 \\
\hline Jan-May X Dispute & $\beta_{1}$ & 0.105 & 1.18 & -0.113 & -1.30 & -0.179 & -1.44 \\
\hline Jan-May X Focal & $\beta_{0}^{F}$ & 0.051 & 0.49 & 0.485 & 5.30 & 0.903 & 6.53 \\
\hline Jan-May X Dispute X Focal & $\beta_{1}^{F}$ & -0.005 & -0.03 & -0.642 & -4.17 & -0.723 & -3.39 \\
\hline Ad spend & $\gamma$ & 2.33E-08 & 1.14 & $1.58 \mathrm{E}-08$ & 0.74 & $8.86 \mathrm{E}-08$ & 1.73 \\
\hline
\end{tabular}

(3) pages

\begin{tabular}{|c|c|c|c|c|c|c|c|}
\hline & & coeff & t-stat & coeff & t-stat & coeff & t-stat \\
\hline Jan-May & $\overline{\beta_{0}}$ & 0.549 & 6.72 & 0.398 & 7.53 & 0.496 & 6.74 \\
\hline Jan-May X Dispute & $\beta_{1}$ & -0.066 & -0.64 & -0.107 & -1.39 & -0.094 & -0.95 \\
\hline Jan-May X Focal & $\beta_{0}^{F}$ & 0.426 & 2.89 & 0.346 & 4.09 & 0.805 & 6.91 \\
\hline Jan-May X Dispute X Focal & $\beta_{1}^{F}$ & -0.561 & -3.00 & -0.360 & -2.69 & -0.689 & -4.25 \\
\hline Ad spend & $\gamma$ & $2.50 \mathrm{E}-08$ & 1.06 & $2.15 \mathrm{E}-08$ & 1.11 & $1.98 \mathrm{E}-07$ & 4.70 \\
\hline $\mathrm{N}$ obs & \multirow{4}{*}{\multicolumn{7}{|c|}{$\begin{array}{l}327,614 \\
83,991 \\
\text { id, year, year X focal } \\
\text { id }\end{array}$}} \\
\hline $\mathrm{N}$ id & & & & & & & \\
\hline Fixed effects & & & & & & & \\
\hline Cluster & & & & & & & \\
\hline
\end{tabular}

Note: Tables present diff-in-diff analyses, using Lonely Planet as a control, for each of the three dependant variables (1) sites, (2) duration and (3) pages. Only the last two months of searches are used. Each table presents 3 separate regressions run for each of the impacted domains, aa.com, orbitz.com and expedia.com. Jan-May is an indicator for the five months January-May, Dispute is an indicator for the year of the dispute 2011, Focal is an indicator for the impacted domain $\boldsymbol{\beta}_{\mathbf{1}}^{\boldsymbol{F}}$ is the relevant treatment effect. 
Table 28: Remove outliers

\begin{tabular}{|c|c|c|c|c|c|c|c|}
\hline \multirow{2}{*}{ (1) sites } & & \multicolumn{2}{|c|}{ aa.com } & \multicolumn{2}{|c|}{ orbitz.com } & \multicolumn{2}{|c|}{ expedia.com } \\
\hline & & \multirow[b]{2}{*}{ coeff } & \multirow[b]{2}{*}{ t-stat } & \multirow[b]{2}{*}{ coeff } & \multirow[b]{2}{*}{ t-stat } & \multirow[b]{2}{*}{ coeff } & \multirow[b]{2}{*}{ t-stat } \\
\hline & & & & & & & \\
\hline Jan-May & $\beta_{0}$ & 0.009 & 3.43 & 0.013 & 3.87 & 0.016 & 3.79 \\
\hline Jan-May X Dispute & $\beta_{1}$ & -0.003 & -0.60 & -0.001 & -0.13 & 0.005 & $5 \quad 0.59$ \\
\hline Jan-May X Focal & $\beta_{0}^{F}$ & -0.005 & -0.63 & 0.032 & 3.54 & 0.058 & 3.57 \\
\hline Jan-May X Dispute X Focal & $\beta_{1}^{F}$ & 0.019 & 1.67 & -0.041 & -2.35 & -0.061 & -2.93 \\
\hline Ad spend & $\gamma$ & 4.77E-09 & 2.27 & $2.33 \mathrm{E}-09$ & 0.90 & $1.84 \mathrm{E}-08$ & 3.29 \\
\hline \multicolumn{8}{|l|}{ (2) duration } \\
\hline & & coeff & t-stat & coeff & t-stat & coeff & t-stat \\
\hline Jan-May & $\beta_{0}$ & 0.026 & 1.31 & 0.063 & 3.12 & 0.087 & 3.02 \\
\hline Jan-May X Dispute & $\beta_{1}$ & 0.035 & 1.10 & -0.011 & -0.33 & 0.003 & $3 \quad 0.07$ \\
\hline Jan-May X Focal & $\beta_{0}^{F}$ & -0.055 & -0.95 & 0.243 & 4.01 & 0.619 & 7.36 \\
\hline Jan-May X Dispute X Focal & $\beta_{1}^{F}$ & 0.127 & 1.36 & -0.305 & -3.18 & -0.376 & -2.72 \\
\hline Ad spend & $\gamma$ & $3.64 \mathrm{E}-08$ & 2.30 & 7.29E-09 & 0.49 & $8.23 \mathrm{E}-08$ & 3.43 \\
\hline \multicolumn{8}{|l|}{ (3) pages } \\
\hline & & coeff & t-stat & coeff & t-stat & coeff & t-stat \\
\hline Jan-May & $\beta_{0}$ & 0.081 & 3.66 & 0.077 & 3.95 & 0.086 & 3.51 \\
\hline Jan-May X Dispute & $\beta_{1}$ & -0.010 & -0.26 & -0.011 & -0.37 & 0.011 & 0.27 \\
\hline Jan-May X Focal & $\beta_{0}^{F}$ & 0.294 & 4.41 & 0.206 & 3.66 & 0.612 & 8.69 \\
\hline Jan-May X Dispute X Focal & $\beta_{1}^{F}$ & -0.252 & -2.20 & -0.040 & -0.44 & -0.225 & -1.88 \\
\hline Ad spend & $\gamma$ & $3.38 \mathrm{E}-08$ & 1.98 & $2.12 \mathrm{E}-08$ & 1.60 & $1.47 \mathrm{E}-07$ & 5.04 \\
\hline $\mathrm{N}$ obs & \multicolumn{7}{|c|}{521,178} \\
\hline $\mathrm{N}$ id & \multicolumn{7}{|c|}{83,869} \\
\hline Fixed eff & \multicolumn{7}{|c|}{ id, year, year X focal } \\
\hline Cluster & \multicolumn{7}{|c|}{ id } \\
\hline
\end{tabular}


Table 29: Searches on impacted domains, relative to Lonely Planet and pooled control period assuming the dispute lasted 3 months

\begin{tabular}{|c|c|c|c|c|c|c|c|}
\hline \multirow{2}{*}{ (1) sites } & & \multicolumn{2}{|c|}{ aa.com } & \multicolumn{2}{|c|}{ orbitz.com } & \multicolumn{2}{|c|}{ expedia.com } \\
\hline & & coeff & t-stat & coeff & t-stat & coeff & t-stat \\
\hline Jan-May & $\beta_{0}$ & 0.009 & 3.33 & 0.014 & 3.88 & 0.015 & 3.58 \\
\hline Jan-May X Dispute & $\beta_{1}$ & 0.003 & 0.61 & 0.008 & 1.28 & 0.011 & 1.55 \\
\hline Jan-May X Focal & $\beta_{0}^{F}$ & -0.008 & -1.06 & 0.025 & 2.62 & 0.058 & 4.42 \\
\hline Jan-May X Dispute X Focal & $\beta_{1}^{F}$ & 0.001 & 0.05 & -0.039 & -2.47 & -0.048 & -2.35 \\
\hline Ad spend & $\gamma$ & $5.90 \mathrm{E}-09$ & 2.72 & $2.88 \mathrm{E}-09$ & 1.13 & $1.35 \mathrm{E}-08$ & 2.53 \\
\hline \multicolumn{8}{|l|}{ (2) duration } \\
\hline & & coeff & t-stat & coeff & t-stat & coeff & t-stat \\
\hline Jan-May & $\beta_{0}$ & 0.045 & 1.47 & 0.060 & 2.09 & 0.092 & 2.25 \\
\hline Jan-May X Dispute & $\beta_{1}$ & 0.070 & 1.47 & 0.039 & 0.89 & 0.014 & 0.22 \\
\hline Jan-May X Focal & $\beta_{0}^{F}$ & 0.006 & 0.07 & 0.266 & 3.06 & 0.738 & 5.87 \\
\hline Jan-May X Dispute X Focal & $\beta_{1}^{F}$ & -0.153 & -1.05 & -0.387 & -3.04 & -0.411 & -2.15 \\
\hline Ad spend & $\gamma$ & $5.68 \mathrm{E}-08$ & 2.53 & $3.37 \mathrm{E}-08$ & 1.39 & $5.70 \mathrm{E}-08$ & 1.30 \\
\hline \multicolumn{8}{|l|}{ (3) pages } \\
\hline & & coeff & t-stat & coeff & t-stat & coeff & t-stat \\
\hline Jan-May & $\beta_{0}$ & 0.050 & 1.23 & 0.046 & 1.65 & 0.038 & 1.01 \\
\hline Jan-May X Dispute & $\beta_{1}$ & 0.045 & 0.71 & 0.057 & 1.45 & 0.078 & 1.45 \\
\hline Jan-May X Focal & $\beta_{0}^{F}$ & 0.470 & 3.44 & 0.244 & 3.17 & 0.471 & 4.40 \\
\hline Jan-May X Dispute X Focal & $\beta_{1}^{F}$ & -0.756 & -3.51 & -0.132 & -1.13 & -0.027 & -0.17 \\
\hline Ad spend & $\gamma$ & $6.08 \mathrm{E}-08$ & 1.87 & $3.12 \mathrm{E}-08$ & 1.86 & $1.80 \mathrm{E}-07$ & 4.63 \\
\hline $\mathrm{N}$ obs & \multirow{4}{*}{\multicolumn{7}{|c|}{$\begin{array}{l}525,300 \\
83,991 \\
\text { id, year, year X focal } \\
\text { id }\end{array}$}} \\
\hline $\mathrm{N}$ id & & & & & & & \\
\hline Fixed effects & & & & & & & \\
\hline Cluster & & & & & & & \\
\hline
\end{tabular}


Table 30: Site visits for consumers living near airports with varying degrees of American presence: diff analysis

\begin{tabular}{|c|c|c|c|c|c|c|}
\hline \multicolumn{7}{|c|}{ (1) No American Airlines serving nearby airports } \\
\hline & \multicolumn{2}{|c|}{ aa.com } & \multicolumn{2}{|c|}{ orbitz.com } & \multicolumn{2}{|c|}{ expedia.com } \\
\hline & coeff & t-stat & coeff & t-stat & coeff & t-stat \\
\hline Jan-May & -0.022 & -0.69 & 0.160 & 1.42 & 0.318 & 1.34 \\
\hline Jan-May X Dispute & $\delta_{1} \quad 0.010$ & 0.13 & -0.064 & -0.44 & -0.308 & -1.22 \\
\hline N obs & 1,203 & & & & & \\
\hline $\mathrm{N}$ & 469 & & & & & \\
\hline
\end{tabular}

(2) American is most important airline in nearest airport

\begin{tabular}{|c|c|c|c|c|c|c|c|}
\hline & \multicolumn{2}{|c|}{ aa.com } & \multicolumn{2}{|c|}{ orbitz.com } & \multicolumn{2}{|c|}{ expedia.com } \\
\hline & & coeff & t-stat & coeff & t-stat & coeff & t-stat \\
\hline Jan-May & $\delta_{0}$ & 0.032 & 1.42 & 0.024 & 0.76 & 0.057 & 1.97 \\
\hline Jan-May X Dispute & $\delta_{1}$ & -0.016 & -0.44 & 0.043 & 0.92 & 0.005 & 0.12 \\
\hline $\mathrm{N}$ obs & & 899 & & & & & \\
\hline $\mathrm{N}$ & 20 & 248 & & & & & \\
\hline
\end{tabular}

(3) Airport is neither American-absent or American-important

\begin{tabular}{llrrrrrr}
\hline & \multicolumn{3}{c}{ aa.com } & \multicolumn{2}{c}{ orbitz.com } & \multicolumn{2}{c}{ expedia.com } \\
& & coeff & t-stat & coeff & \multicolumn{1}{c}{ t-stat } & coeff & \multicolumn{1}{c}{ t-stat } \\
\hline Jan-May & $\delta_{0}$ & 0.012 & 1.31 & 0.071 & 6.56 & 0.119 & 6.47 \\
Jan-May X Dispute & $\boldsymbol{\delta}_{\mathbf{1}}$ & $\mathbf{0 . 0 2 6}$ & $\mathbf{1 . 6 7}$ & $\mathbf{- 0 . 0 6 3}$ & $\mathbf{- 3 . 1 1}$ & $\mathbf{- 0 . 0 4 8}$ & $\mathbf{- 1 . 6 5}$ \\
\hline N obs & 190,514 & & & & & \\
N & 60,788 & & & & & \\
\hline
\end{tabular}

\begin{tabular}{lllrrrrr} 
All data & \multicolumn{1}{c}{ aa.com } & \multicolumn{2}{c}{ orbitz.com } & \multicolumn{2}{c}{ expedia.com } \\
& \multicolumn{2}{c}{ coeff } & t-stat & coeff & t-stat & coeff & t-stat \\
\hline Jan-May & $\delta_{0}$ & 0.017 & 1.89 & 0.056 & 5.12 & 0.100 & 6.51 \\
Jan-May X Dispute & $\boldsymbol{\delta}_{\mathbf{1}}$ & $\mathbf{0 . 0 1 6}$ & $\mathbf{1 . 1}$ & $\mathbf{- 0 . 0 3 5}$ & $\mathbf{- 1 . 9 1}$ & $\mathbf{- 0 . 0 3 7}$ & $\mathbf{- 1 . 5 2}$ \\
\hline N obs & 258,201 & & & & & \\
N & 82,886 & & & & & \\
\hline
\end{tabular}

Note: This table presents a diff analysis for visits to the treated domains for three subsets of the data, 1) airports with No American presence, 2) Airports where American is the most important airline and 3) the rest. The hypothesis is that we will see the strongest effect of the dispute in susbet (3), because this is where the role of aggregators is most relevant. For reference, analysis using All data is also presented. $\boldsymbol{\delta}_{\mathbf{1}}$ is the relevant treatment effect. 
Table 31: Site visits for consumers living near airports with varying degrees of competition: diff analysis

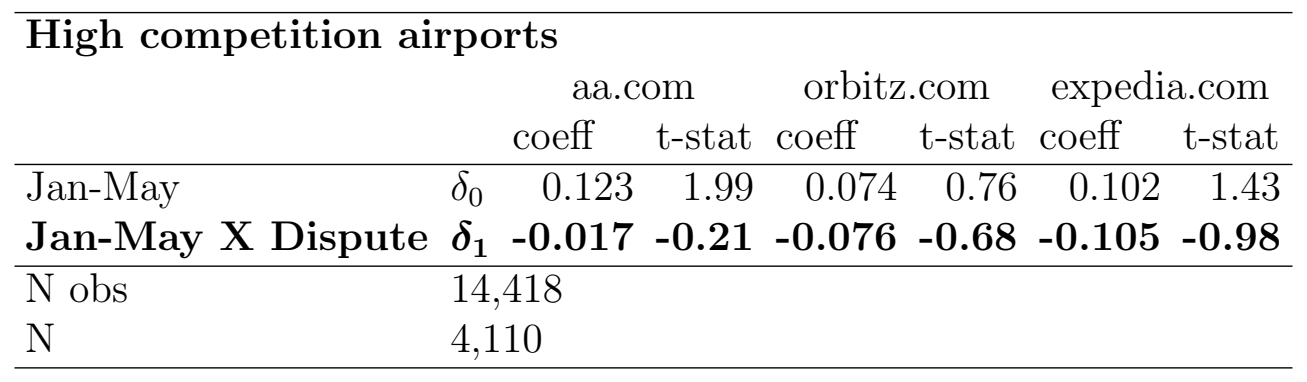

Low competition airports

\begin{tabular}{llrrrrrr}
\hline & \multicolumn{3}{c}{ aa.com } & \multicolumn{2}{c}{ orbitz.com } & \multicolumn{2}{c}{ expedia.com } \\
& \multicolumn{2}{c}{ coeff } & t-stat & coeff & t-stat & coeff & t-stat \\
\hline Jan-May & $\delta_{0}$ & 0.015 & 1.27 & 0.064 & 3.57 & 0.117 & 4.72 \\
Jan-May X Dispute & $\boldsymbol{\delta}_{\mathbf{1}}$ & $\mathbf{0 . 0 3 6}$ & $\mathbf{1 . 4}$ & $\mathbf{- 0 . 0 7 5}$ & $\mathbf{- 3 . 0 4}$ & $\mathbf{- 0 . 0 6 7}$ & $\mathbf{- 1 . 6 7}$ \\
\hline N obs & 62,628 & & & & & \\
N & 19,312 & & & & & \\
\hline
\end{tabular}

